\title{
The Expression of TAG-1 in Glial Cells Is Sufficient for the Formation of the Juxtaparanodal Complex and the Phenotypic Rescue of Tag-1 Homozygous Mutants in the CNS
}

\author{
Maria Savvaki, ${ }^{1}$ Kostas Theodorakis, ${ }^{1}$ Lida Zoupi, ${ }^{1}$ Antonis Stamatakis, ${ }^{2}$ Simona Tivodar, ${ }^{1}$ Kyriacos Kyriacou, ${ }^{3}$ \\ Fotini Stylianopoulou, ${ }^{2}$ and Domna Karagogeos ${ }^{1}$ \\ ${ }^{1}$ Department of Basic Science, Faculty of Medicine, University of Crete and Institute of Molecular Biology and Biotechnology-Foundation for Research and \\ Technology, 71110, Heraklion, Crete, Greece, ${ }^{2}$ Laboratory of Biology-Biochemistry, School of Nursing, University of Athens, Athens 11527 , Greece, \\ and ${ }^{3}$ Department of Molecular Pathology and Electron Microscopy, The Cyprus Institute of Neurology and Genetics, 1683 Nicosia, Cyprus
}

\begin{abstract}
Myelinated fibers are organized into specialized domains that ensure the rapid propagation of action potentials and are characterized by protein complexes underlying axoglial interactions. TAG-1 (Transient Axonal Glycoprotein-1), a cell adhesion molecule of the Ig superfamily, is expressed by neurons as well as by myelinating glia. It is essential for the molecular organization of myelinated fibers as it maintains the integrity of the juxtaparanodal region through its interactions with Caspr2 and the voltage-gated potassium channels (VGKCs) on the axolemma. Since TAG-1 is the only known component of the juxtaparanodal complex expressed by the glial cell, it is important to clarify its role in the molecular organization of juxtaparanodes. For this purpose, we generated transgenic mice that exclusively express TAG-1 in oligodendrocytes and lack endogenous gene expression $\left(\right.$ Tag- $1^{-1-} ;$ plp $\left.{ }^{\text {Tg(rTag- }-1)}\right)$. Phenotypic analysis clearly demonstrates that glial TAG-1 is sufficient for the proper organization and maintenance of the juxtaparanodal domain in the CNS. Biochemical analysis shows that glial TAG-1 physically interacts with Caspr2 and VGKCs. Ultrastructural and behavioral analysis of Tag-1 ${ }^{-1-} ;$ plp ${ }^{\text {Tg(rTag-1) }}$ mice shows that the expression of glial TAG-1 is sufficient to restore the axonal and myelin deficits as well as the behavioral defects observed in Tag-1 $1^{-l-}$ animals. Together, these data highlight the pivotal role of myelinating glia on axonal domain differentiation and organization.
\end{abstract}

\section{Introduction}

Myelinated fibers are organized into specialized and molecularly defined domains that ensure the coordinated function of voltageactivated sodium and potassium channels essential for the rapid propagation of the action potentials (Girault and Peles, 2002; Poliak and Peles, 2003; Salzer, 2003; Salzer et al., 2008). The node of Ranvier is a myelin-free region, characterized by a high concentration of sodium channels. Next to it, the paranodal glial

Received May 13, 2010; revised July 26, 2010; accepted Aug. 22, 2010.

This work was supported by the European Leukodystrophy Association (ELA Research Foundation, Grant 2007025I), National Society for Multiple Sclerosis, Grant RG3368-A-1; United Kingdom Multiple Sclerosis Society, Grant 874/07; and Institute of Molecular Biology and Biotechnology intramural grants (to D.K.). M.S. has been the recipient of the Manasaki Fellowship of the University of Crete and is a graduate student of the program Molecular Basis of Human Diseases. L.Z. is a graduate student of the program Molecular Biology and Biomedicine. We thank Dr. Stavros Malas at the Cyprus Institute of Neurology and Genetics for the generation of transgenic lines, Kostis Kourouniotis and Niki Vardouli for animal care, and Dr. Yannis Dalezios for help with the ultrastructural studies. We thank Drs. B. Fuss and W. Macklin for the plp cassette and Drs. E. Peles, D. Sherman, and L. Goutebroze for reagents. We acknowledge the help of Panayiota Miltiadous with the behavioral analysis and Michalis Mamantopoulos with immunohistochemistry. We also thank Drs. K. Kleopa, B. Popko, and M. Traka for helpful discussions and the members of the Karagogeos lab for comments on this manuscript.

Correspondence should be addressed to Domna Karagogeos, Department of Basic Science, Faculty of Medicine, University of Crete and Institute of Molecular Biology and Biotechnology-Foundation for Research and Technology, Vassilika Vouton, 71110, Heraklion, Crete, Greece. E-mail: karagoge@imbb.forth.gr.

DOI:10.1523/JNEUROSCI.2574-10.2010

Copyright $\odot 2010$ the authors $\quad$ 0270-6474/10/3013943-12\$15.00/0 loops tightly interact with the axon to form the paranodal junction, which insulates the node from the periaxonal internode. The paranodal complex comprises of the neurexin protein Caspr on the axon, and the Ig superfamily (IgSF) members contactin and neurofascin 155 on the axon and glial cell surface, respectively (Peles et al., 1997; Volkmer et al., 1998; Faivre-Sarrailh et al., 2000; Charles et al., 2002). Juxtaparanodes are the regions of the internode adjacent to the paranodes.

Juxtaparanodes are characterized by a molecular complex consisting of TAG-1 (axonin-1/contactin-2), an adhesion molecule of the IgSF present on the glial and axonal membranes, as well as by the neurexin protein Caspr2 and the Shaker-type voltage-gated potassium channels (VGKCs) on the axon (Poliak et al., 2003; Traka et al., 2003; Tzimourakas et al., 2007). The absence of either TAG-1 or Caspr2 results in disruption of this complex and the subsequent diffusion of VGKCs (Poliak et al., 2003; Traka et al., 2003).

TAG-1 is expressed in many neuronal subpopulations as a glycosyl-phosphatidyl-inositol anchored form as well as a released form, and is implicated in neurogenesis, neurite extension, and fasciculation (Furley et al., 1990; Stoeckli et al., 1991; Kunz et al., 1998; Fitzli et al., 2000; Denaxa et al., 2001; Kyriakopoulou et al., 2002; Liu and Halloran, 2005; Ma et al., 2008; Mattson and 
van Praag, 2008; Wolman et al., 2008; Lieberoth et al., 2009). In the adult, TAG- 1 is expressed by neurons and by myelinating glia. It is vital in organizing the juxtaparanodes of myelinated fibers and it plays an important role in optic nerve structural organization (Traka et al., 2002, 2003; Chatzopoulou et al., 2008). The protein is also important in regulating several behavioral aspects since mice deficient for TAG-1 $\left(\mathrm{Tag}^{-1^{-1-}}\right)$ display behavioral deficits such as impaired learning and memory as well as sensorimotor gating and gait coordination defects (Fukamauchi et al., 2001; Savvaki et al., 2008).

TAG-1 is the only partner of the juxtaparanodal complex identified so far on the glial cell side. Our aim was to explore the mechanisms myelinating glia use to organize this complex and, in particular, to explore the role of TAG-1 expressed by oligodendrocytes in this process. We generated transgenic mice that exclusively express the rat homolog of TAG-1 in oligodendrocytes under the proteolipid protein gene $(p l p)$ promoter in the Tag $1^{-1-}$ background $\left(\right.$ Tag- $1^{-1-} ;$ plp $\left.p^{\text {Tg(rTag-1) }}\right)$ and investigated its role in juxtaparanodal complex formation, behavior, myelination, and optic nerve organization. We demonstrate that glial TAG-1 is sufficient for the restoration of the juxtaparanodal complex and rescues the optic nerve defects and the behavioral deficits of the homozygous mutant mice.

\section{Materials and Methods}

\section{Animals}

The generation of Tag-1 $1^{-1-}$ mice has previously been described (Fukamauchi et al., 2001; Traka et al., 2003). All mice were kept in heterozygote breeding pairs and the genotypes were confirmed by PCR. The housing and animal procedures used were in agreement with the European Union policy (Directive 86/609/EEC) and according to institutionally approved protocols.

\section{Generation of Tag- $1^{-/-} ; \mathrm{plp}^{\mathrm{Tg}(\mathrm{rTag}-1)}$ transgenic mice}

Transgenic mice that express the rat homolog of TAG-1 (rTAG-1) under the $p l p$ promoter were generated. The plp promoter was isolated from the original plp promoter cassette (Wight et al., 1993; Fuss et al., 2000) and inserted into ApaI/SacII sites of the pBLscKS-II plasmid vector. The cDNA of rTAG-1 was subsequently inserted into SacII/EcoRV sites of the same plasmid vector. Donor mice were superovulated and single cell embryos were harvested. The plp-rTag- 1 cassette was isolated and injected into one of the pronuclei of F2 C57BL/ $6 \times \mathrm{DBA} / 2$ donor embryos. Injected embryos were transferred into pseudopregnant females. Born pups were weaned and tailed. Positive founders were identified by PCR amplification of tail DNA, using a plp 5'UTR-forward (5'AAGGAGACTGGAGAGACCAGG- $\left.3^{\prime}\right)$ and a rTag- 1 reverse (5'GAATCAACTGGAGACTCAGGC- $3^{\prime}$ ) primer sequence. Founders were mated to C57B110/CBA mice and their offspring were tested for the transgene with PCR amplification of tail DNA. Five transgenic lines were finally obtained. We analyzed four of five lines (named RT38, RT29, RT6, and RT20), which expressed the rat homolog of TAG-1 in various areas of the CNS, as revealed by immunohistochemistry. Analysis of the fifth line (RT27) was not possible due to infertility problems. Transgenic mice were backcrossed in the Tag-1 ${ }^{-/-}$background (C57B110/CBA) to obtain expression of rTAG-1 protein exclusively from glial cells and the genotypes were confirmed by PCR. All four lines expressed the rTAG-1 homolog in oligodendrocytes and had similar phenotypes (supplemental Fig. 1, available at www.jneurosci.org as supplemental material). The RT38 line was finally chosen for extensive analyses and will be referred as Tag-1 ${ }^{-1-} ; p l p^{\text {Tg(rTag-1) }}$ in this paper. Two of four transgenic lines expressed rTAG-1 in Schwann cells (RT6 and RT38) (RT38 line is shown in supplemental Fig. 4, available at www.jneurosci.org as supplemental material).

\section{Immunohistochemistry}

Optic nerves, cerebellum, and the two hemispheres (including hippocampus and entorhinal cortex) were isolated from mice after perfusion with $4 \%$ paraformaldehyde (PFA) in $0.1 \mathrm{M}$ PBS. Tissues were then fixed in the same fixative for $30 \mathrm{~min}$ at $4^{\circ} \mathrm{C}$, cryoprotected in $30 \%$ sucrose in $0.1 \mathrm{~m}$ PBS, and embedded in $7.5 \%$ gelatin/15\% sucrose gel. Cryosections of $10 \mu \mathrm{m}$ were obtained and mounted on Superfrost Plus microscope slides (O. Kindler), postfixed in ice-cold acetone for $10 \mathrm{~min}$, blocked in 5\% BSA in $0.1 \mathrm{M}$ PBS, and incubated with primary and secondary antibodies in 5\% BSA (Sigma-Aldrich), $0.5 \%$ Triton-X in $0.1 \mathrm{M}$ PBS. Sciatic nerves were also isolated and fixed in $2 \%$ PFA in $0.1 \mathrm{M} \mathrm{PBS}$ for $30 \mathrm{~min}$ at room temperature. Teasing of the nerves was performed as previously described (Traka et al., 2003; Tzimourakas et al., 2007). Slides mounted with fibers were postfixed in ice-cold acetone for $10 \mathrm{~min}$, blocked in 10\% FBS (Invitrogen), 0.5\% teleostean gelatin (SigmaAldrich), and $0.1 \%$ Triton-X in $0.1 \mathrm{M}$ PBS, and incubated with primary and secondary antibodies in 1\% FBS, $0.5 \%$ teleostean gelatin, and $0.1 \%$ Triton-X in 0.1 M PBS. Slides were mounted using Mowiol (Calbiochem) and the samples were observed in a confocal microscope (TCS SP2; Leica).

The following antibodies were used for immunohistochemistry: mouse monoclonal anti-rTAG-1 antibody that recognizes rat TAG-1 protein (hereafter called anti-rTAG-1 and used to recognize the transgenic protein) (1c12, 1:2000; Developmental Studies Hybridoma Bank), rabbit polyclonal antibody against TAG-1 (1:1000, recognizes the protein from mouse and rat, hereafter called anti-TAG-1), rabbit polyclonal antibody against Olig2 (1:1000; Millipore Bioscience Research Reagents), mouse monoclonal antibody against NeuN (1:400; Millipore Bioscience Research Reagents), rabbit polyclonal antibodies against Caspr2 and Caspr (both 1:800; gifts from Dr. Laurence Goutebroze, Inserm 536, Paris, France), mouse monoclonal antibody against Caspr (1:1000; a gift from Dr. Elior Peles, Weizmann Institute of Science, Rehovot, Israel), rabbit polyclonal antibody against Kv1.2 (Alomone, 1:200), rabbit polyclonal antibodies against Neurofascins (NF) 155 and NF186 (1:200 and 1:4000, respectively; gifts from Drs. Sherman and Tait, University of Edinburgh, Edinburgh, UK), and fluorochrome-labeled secondary antibodies Alexa Fluor 488 and 555 (1:800; Invitrogen). To-Pro 3 iodide (Invitrogen) was also used for the visualization of the nuclei.

For the quantification of properly clustered juxtaparanodes, optic nerve sections were stained with antibodies against Caspr and Caspr2 as well as Caspr and Kv1.2, as described above, to denote paranodes and juxtaparanodes and confocal images were obtained. A square area of $93 \times 93 \mu \mathrm{m}$ was examined to count all stained juxtaparanodes and the percentage of paranodes with stained juxtaparanodes to total paranodes was calculated. Four to five different areas from each mouse were examined. The counts in each area were pooled from all animals belonging to the same genotype and average counts were obtained for each genotype. Optic nerves from two age-matched wild-type mice $\left(\right.$ Tag- $\left.1^{+/+}\right)$were analyzed and displayed no statistically significant difference compared with Tag- $1^{+/-}$animals (mean for percentage-clustered Caspr2, 70.08 and 70.60, respectively; mean for percentage-clustered Kv1.2, 67.02 and 64.09 , respectively). Therefore, we used Tag- $1^{+1-}$ as controls in all immunohistochemical experiments. Littermate animals $\left(\right.$ Tag- $1^{+1-}$, Tag- $1^{-1-}$, and Tag- $1^{-1-} ; p l p^{\text {Tg(rTag-1) }} ; n=3$ ) were used for the juxtaparanodal phenotype analysis. In all cases, data are presented as mean \pm SEM. Statistical analysis was performed using Student's $t$ test.

\section{Primary cultures of mixed glial cells and immunofluorescence} Primary cultures of mixed glial cells were obtained by isolation of cerebral cortices from postnatal day 2 (P2) Tag- $1^{+/-}, \mathrm{Tag}-1^{-1-}$, or Tag-1 ${ }^{-1-}$; $p l p^{T g(r T a g-1)}$ transgenic mice. Tissues were transferred in 10-cm-diameter plates containing DMEM with $10 \%$ FBS, cut into small pieces and submitted to enzymatic digestion with $1 \%$ trypsin (Invitrogen), $20 \mathrm{U} / \mathrm{ml}$ DNase I, and 25 mM HEPES in MEM (Invitrogen) for $15 \mathrm{~min}$ at $37^{\circ} \mathrm{C}$. Digestion was stopped with the addition of $10 \%$ FBS in DMEM (SigmaAldrich). Tissue lysates were centrifuged at $1100 \mathrm{rpm}$ for $5 \mathrm{~min}$, titrated with glass Pasteur pipette, and washed twice with DMEM and 10\% FBS. Cell suspensions were plated on precoated poly-D-lysine (SigmaAldrich), glass coverslips or Petri dishes and fed with DMEM, 10\% FBS, 2 mM L-glutamine (Invitrogen) and N2 supplement (Invitrogen). Microglial removal was achieved mechanically by culture shaking at $37^{\circ} \mathrm{C}$ for 30 min. Primary mixed glial cells were cultured for $3 \mathrm{~d}$ and then the supernatant was removed and frozen, while cultures were fed with fresh me- 
dium for 3 more days before further analysis. Immunofluorescence in living cells for TAG-1 was performed as previously described (Karagogeos et al., 1991; Traka et al., 2002) using a monoclonal anti-rTAG-1 antibody $(1 \mathrm{c} 12,1: 2000)$ for Tag-1 ${ }^{-1-} ;$ plp $p^{\text {Tg(rTag-1) }}$ and a rabbit polyclonal antibody against Olig2 (1:1000; Millipore Bioscience Research Reagents).

\section{Cultures from dissociated P2 cortices and P4 Schwann cells}

P2 cortices were isolated from Tag- $1^{+/+}$and Tag- $1^{-\prime-} ; p_{1} p^{\text {Tg(rTag- }-1)}$ mice and submitted to a brief enzymatic digestion in $0.25 \%$ trypsin + EDTA (Invitrogen) and a subsequent mechanical dissociation via a glass Pasteur pipette. Cell suspensions were plated on glass coverslips precoated with Matrigel (BD Biosciences), and fed with Neurobasal medium (Invitrogen), 10\% FBS, and B27 supplement (Invitrogen). After $48 \mathrm{~h}$ in culture, immunocytochemistry was performed using monoclonal antirTAG-1 antibody (1c12, 1:2000), a rabbit polyclonal antibody against Olig2 (1:1000; Millipore Bioscience Research Reagents), a rabbit polyclonal antibody for TAG-1 (1:1000), and a mouse monoclonal antiNeuN antibody (1:400; Millipore Bioscience Research Reagents), as previously described (Traka et al., 2002). Schwann cell cultures were obtained from P4 Tag-1 $1^{+/+}$and Tag- $1^{-{ }^{-}} ;$plp $p^{\text {Tg(rTag-1) }}$ mouse sciatic nerves, as previously described (Traka et al., 2002). Schwann cells were kept in culture for $4 \mathrm{~d}$ and then immunostained with antibodies against TAG-1, as previously described (Traka et al., 2002).

\section{Western blot analysis and immunoprecipitation}

Tissues were collected from freshly killed adult mice and homogenized directly in ice-cold $85 \mathrm{~mm}$ Tris, $\mathrm{pH}$ 7.5, $30 \mathrm{~mm} \mathrm{NaCl}, 1 \mathrm{~mm}$ EDTA, 120 mu glucose, $1 \%$ Triton X-100, $60 \mathrm{~mm}$ octyl Q-D glucopyranoside (Sigma-Aldrich), and protease inhibitor mixture diluted 1:1000 (SigmaAldrich), followed by a brief sonication on ice. The total protein in each sample was quantified with the Bradford kit (Bio-Rad Laboratories). Protein extracts were analyzed by SDS PAGE and electrotransferred to $0.45 \mu \mathrm{m}$ Protran nitrocellulose transfer membrane (Whatman) for $1 \mathrm{~h}$ using a wet transfer unit (Bio-Rad Laboratories). Following $1 \mathrm{~h}$ blocking (5\% powdered skim milk and $0.1 \%$ Tween 20 in $0.1 \mathrm{M}$ PBS), the membrane was incubated overnight with the primary antibodies. After washing three times for $10 \mathrm{~min}$ in $0.1 \%$ Tween 20 in $0.1 \mathrm{M}$ PBS, samples were incubated for $1 \mathrm{~h}$ at room temperature with horseradish peroxidasecoupled secondary antibodies and proteins were visualized by enhanced chemiluminescence (Pierce). Colloidal Coomassie blue kit (Invitrogen) was used in some cases for the staining of proteins in SDS polyacrylamide gels.

The following antibodies were used for Western blot (WB) analysis: rabbit polyclonal antibodies against TAG-1 (1:4000), rat monoclonal antibody against MBP (1:2000; Serotec), rabbit polyclonal antibody against PLP (1:1000; Abcam), rabbit polyclonal antibody against neurofilaments M (1:5000; Covance), rabbit polyclonal antibodies against Caspr2 and Caspr (both 1:3000; gifts from Dr. Laurence Goutebroze, Inserm 536, Paris, France), rabbit polyclonal antibody against Kv1.2 (Alomone, 1:1000), mouse monoclonal antibody against actin (1:4000; Millipore Bioscience Research Reagents), and horseradish peroxidase-coupled secondary antibodies (1:3000-5000; GE Healthcare).

For immunoprecipitation (IP), adult mouse and rat brain protein extracts were obtained as described above, whereas cultured HEK293 cells were washed twice in $0.1 \mathrm{M}$ PBS and then lysed using the previously mentioned buffer. The lysates were then subjected to centrifugation at $13,000 \mathrm{rpm}$ at $4^{\circ} \mathrm{C}$ for $30 \mathrm{~min}$. Protein extracts were precleared with protein G Sepharose beads (GE Healthcare) for $1 \mathrm{~h}$ at $4^{\circ} \mathrm{C}$. IP was performed by incubating the samples with $1.3 \mu \mathrm{l}$ of mouse monoclonal anti-rTAG-1 antibody (1c12; Developmental Studies Hybridoma Bank), and $40 \mu \mathrm{l}$ of protein $\mathrm{G}$ Sepharose beads on a rotating platform overnight at $4^{\circ} \mathrm{C}$. After a brief centrifugation at $6000 \mathrm{rpm}$, the supernatants were removed, and the beads were washed four times with wash buffer $(5 \mathrm{~mm}$ Tris-HCl, pH 8.0, 1\% Triton X-100, 50 mм NaCl, $2.5 \mathrm{~mm} \mathrm{CaCl}_{2}, 2.5 \mathrm{~mm}$ $\mathrm{MgCl})$, and resuspended in equal volume of $2 \times$ SDS loading buffer.

\section{Purification of myelin and axonal fractions}

For the myelin and axonal fractionation, brain samples were collected from freshly killed mice, directly diluted in $150 \mathrm{~mm} \mathrm{NaCl}, 1.2 \mathrm{M}$ sucrose,
$10 \mathrm{~mm}$ TES, pH 7.5 (Sigma-Aldrich), and homogenized with Dounce homogenizer. After a $20 \mathrm{~min}$ centrifugation at $82,500 \times \mathrm{g}$, the floating layer was collected, further diluted in $150 \mathrm{~mm} \mathrm{NaCl}, 1 \mathrm{M}$ sucrose, $10 \mathrm{~mm}$ TES, pH 7.5, and homogenized as described above. Samples were then centrifuged for $20 \mathrm{~min}$ at $82,500 \times \mathrm{g}$. After centrifugation, the floating layer, consisting of the myelin enriched fraction, was suspended in 150 mM NaCl, 0.8 m sucrose, 10 mM TES, pH 7.5, homogenized, and centrifuged at $82,500 \times g$ for $20 \mathrm{~min}$, while the pellet, consisting of the axonal enriched fraction, was resuspended in $5 \mathrm{~mm}$ Tris pH 7.2, $1 \%$ NP-40, $5 \mathrm{~mm}$ EGTA, $1 \mathrm{~mm}$ PMSF. The myelin-enriched fraction was treated with 10 mM EGTA, pH 7.5, homogenized, and stirred for $1 \mathrm{~h}$ at $4^{\circ} \mathrm{C}$. A subsequent centrifugation for $30 \mathrm{~min}$ at $82,500 \times \mathrm{g}$ was performed and the obtained pellet was further homogenized in $0.8 \mathrm{~m}$ sucrose, $1 \mathrm{~mm}$ EGTA, $150 \mathrm{~mm}$ $\mathrm{NaCl}, 10 \mathrm{~mm}$ TES, $\mathrm{pH} 7.5$, buffer and centrifuged at $82,500 \times g$ for 30 $\mathrm{min}$. The floating part, consisting of the purified myelin fraction, after a series of washes with water and $10 \mathrm{~min}$ centrifugations at 22,000 rpm, was resuspended in 5 mм Tris pH 7.2, 1\% NP-40, 5 mм EGTA, 1 mм PMSF. Lysates, axonal, and pure myelin fractions from mouse brains were then subjected to WB analysis.

\section{Cell culture and immunofluorescence}

HEK293 cells were transfected with lipofectamin (Invitrogen) using 10 $\mu \mathrm{g}$ of plasmid per $10-\mathrm{cm}$-diameter dish, $2 \mu \mathrm{g}$ of plasmid per $60-\mathrm{mm}$ diameter dish, or $1.2 \mu \mathrm{g}$ of plasmid per 35-mm-diameter dish. Plasmid constructs for the expression of rTAG-1 (Traka et al., 2003), Caspr (a gift from Dr Laurence Goutebroze, Inserm 536, Paris) (Bonnon et al., 2003), or Caspr2 (Traka et al., 2003) were used. Twenty-four hours after transfection, the transfected cells were used for the detection of a possible interaction between the secreted or the surface-bound form of rTAG-1 with Caspr 2 protein. In the first case, the medium from Tag- $1^{-/-}$; $p l p^{\text {Tg(rTag-1) }}$ mixed glial cell cultures [after $3 \mathrm{~d}$ in vitro (DIV), medium from one brain maximum was used per $35-\mathrm{mm}$-diameter dish] was added to the medium of the growing Caspr2-transfected cells. Twentyfour hours later, the cells were immunostained for rTAG-1 and Caspr2. In the second case, the transfected cells expressing Caspr 2 or Caspr were collected and cultured on top of cells transfected with rTAG-1 expression plasmid (Traka et al., 2003) and vice versa. Twenty-four hours later, the mixed cell populations were immunostained for rTAG-1 and Caspr2 or lysed for IP. Immunofluorescence for TAG- 1 and Caspr 2 was performed as previously described (Traka et al., 2003).

\section{Electron microscopy}

Anesthetized mice were perfused with $2.5 \%$ glutaraldehyde in $0.1 \mathrm{M}$ phosphate buffer (PB), pH 7.3 (primary fixative). Dissected optic nerves were placed in the primary fixative overnight at $4^{\circ} \mathrm{C}$. The fixed optic nerves were thoroughly washed in $0.1 \mathrm{M} \mathrm{PB}$, postfixed in $1 \%$ osmium tetroxide for $1 \mathrm{~h}$, dehydrated in a series of increasing concentrations of alcohol, and embedded in epoxy resin (Durcupan ACM; Fluka). Ultrathin sections $(70-80 \mathrm{~nm}$ ) were cut using an ultramicrotome (EM UC6; Leica), contrasted with lead, and viewed using a transmission electron microscope (100C; JEOL) operating at $80 \mathrm{kV}$. For ultrastructural studies, randomly chosen electron micrographs were taken at 10,000 $\times$ magnification in both the center and the periphery within the medial segment (close to the proximal end) of the optic nerve. Axon diameter and myelin thickness were measured with ImageJ software and statistical analysis was performed using Student's $t$ test. For g ratio and axonal diameter analysis, 13 mice were used (three Tag- $1^{+1+}$, two Tag- ${ }^{+1-}$, four Tag- ${ }^{-1-}$, and four Tag- $\left.1^{-1-} ; p l p^{T g(r \text { Tag-1 })}\right)$. For g ratio, $>100$ axons were measured for each mouse, whereas for axonal diameter, $>200$ axons were analyzed. Unpaired Student's $t$ test analysis was performed for g ratio and diameter comparison. No statistically significant differences were observed between Tag- $1^{+/+}$and Tag- $1^{+/-}$mice regarding their axon diameter and $g$ ratio (0.7077 and 0.7078 , respectively).

\section{Behavioral studies}

Twenty-four males, eight Tag-1 ${ }^{-1-} ;$ plp ${ }^{\text {Tg(rTag-1 })}$, eight Tag-1 ${ }^{-1-}$ mice, and eight Tag- $1^{+/+}$mice were used for the behavioral experiments. Animals were tested successively in a set of behavioral tasks in the following order: cued and hidden version of the Morris water maze (MWM), novel-object recognition, rotarod, and footprint analysis. 
Cued version of the MWM. We used a circular pool ( $85 \mathrm{~cm}$ in diameter) filled with water $\left(24 \pm 1^{\circ} \mathrm{C}\right)$ that was rendered opaque with milk. The protocol followed consisted of a $3 \mathrm{~d}$ visible learning period, where in the absence of extra-maze cues, mice were trained to find a transparent movable platform $(8 \mathrm{~cm} \times 10 \mathrm{~cm})$ submerged $1 \mathrm{~cm}$ below the water surface and marked with a black flag. Mice were subjected to four trials per day (maximum duration, $60 \mathrm{~s}$; separated by 15 min intervals), each from a different starting position along the perimeter of the pool. At the end of each trial, mice were allowed on the platform for $20 \mathrm{~s}$. The behavior of animals was digitally recorded at a frequency of $2-5 \mathrm{~Hz}$ using the Noldus Ethovision system (Ethovision 3.0; Noldus Information Technologies). During the learning phase, latency (time in seconds to reach the platform) was recorded. To ensure that behavior in the water maze did not simply reflect changes in activity, swim speed $(\mathrm{cm} / \mathrm{s})$ was also determined. The values obtained were averaged per mouse within each daily session.

Hidden version of the MWM. Animals were tested as described above for the cued version with the following modifications: the submerged transparent platform $(8 \times 10 \mathrm{~cm})$ was not marked by a flag and the protocol followed consisted of an acquisition training phase and a longterm memory probe trial. In the acquisition phase, mice were trained to find the hidden platform (in a fixed position relative to visible extra-maze cues) across four consecutive daily sessions. Each daily session consisted of four $60 \mathrm{~s}$ trials with four different starting positions (intertrial interval, $15 \mathrm{~min}$ ). At the end of each trial, mice were left on the platform for $20 \mathrm{~s}$. Twenty-four hours after the last acquisition trial, animals were given a probe trial in the absence of the platform ( $60 \mathrm{~s}$ duration, starting position opposite to the target quadrant, i.e., the quadrant in which the platform was located during training). The behavior of animals was digitally recorded at a frequency of $2-5 \mathrm{~Hz}$ using the Noldus Ethovision system (Ethovision 3.0; Noldus Information Technologies).

During the learning phase in the hidden version of the water maze, latency to reach the platform was recorded. The values obtained were averaged per mouse within each daily session. In the probe trial, we analyzed the time spent in the target and opposite quadrants. As in the cued version, to ensure that behavior in the water maze did not simply reflect changes in activity, swim speed $(\mathrm{cm} / \mathrm{s})$ was also determined.

Novel-object recognition. The apparatus consisted of a rectangular arena $(40 \times 40 \mathrm{~cm})$ with a closed-circuit camera above it. During a $3 \mathrm{~d}$ habituation period, mice were allowed to freely explore the arena for 5 min each day. One day after the habituation session, mice were subjected to two 10 min familiarization trials, with a $10 \mathrm{~min}$ intertrial interval in which mice were returned to their home cages. During each familiarization trial, mice were placed at the center of the arena and left to explore two identical objects made of Lego blocks (randomly selected from three differently colored and shaped objects used throughout the experiment: a pyramid-, a П-, and a cube-shaped object, all of equivalent height). Ten minutes after the last familiarization trial, mice were placed in the same arena, where one of the two objects (randomly chosen) was replaced by a novel one (different shape). Time spent observing each object (novel vs familiar object exploration time) was scored and the discrimination index [(time spent observing novel object) - (mean time observing familiar object)/(time spent observing novel object) + (mean time observing familiar object)] was calculated.

Rotarod. Motor balance and coordination was determined using an accelerating rotarod apparatus (ENV-575M; Med Associates). Training of animals consisted of four trials per day (with 15 min rests between trials), for 3 consecutive days. Mice were placed on the rotating rod at 4 $\mathrm{rpm}$ and gradually the speed was increased to $40 \mathrm{rpm}$ at a rate of 0.12 $\mathrm{rpm} / \mathrm{s}$. Each trial lasted until the mouse fell from the rod or for a maximum of $300 \mathrm{~s}$. Testing of the motor coordination abilities of the animals was performed $24 \mathrm{~h}$ after completion of training and consisted of two consecutive sessions of three trials each (maximum duration, $300 \mathrm{~s}$ ), the first session at a constant speed of $20 \mathrm{rpm}$, and the second one at $32 \mathrm{rpm}$. Latency to fall (in seconds) was calculated for each of the training days as well as for each testing speed and used for data analyses.

Footprint analysis. To obtain the footprints, paws were painted with nontoxic colored inks and the mouse was allowed to walk down a narrow, open-top runway covered with white paper. The runway length was
$22 \mathrm{~cm}$ long and the width was $10 \mathrm{~cm}$. Furthermore, the open-top runway was flanked by two walls at each side that were $11 \mathrm{~cm}$ high. The mice were acclimatized to the environment for at least $60 \mathrm{~min}$, and were allowed two practice runs before coloring the paws. To facilitate subsequent analysis, front and hindpaws were colored with different colors: blue for the front and red for the hindpaws. Each mouse was subjected to a total of nine trials (three trials per day for $3 \mathrm{~d}$ ). Once the footprints had dried, the following parameters were measured: overlap width, forelimb stride length, and hindlimb stride length for the left and right limbs separately.

Statistical analysis. The effect of genotype on the latency to reach the platform during the learning period in both the cued and hidden versions of the water maze, as well as on the latency before falling off during training in the rotarod test, was assessed using one-way ANOVA with repeated measures (day) and genotype as the independent factor. The effect of genotype on time spent in the target and opposite quadrants of the Morris water maze during the long-term memory probe trial was assessed using a two-way ANOVA with genotype and quadrant as independent factors. In the case of significant interactions, univariate $F$ tests were used to evaluate the main effects. Finally, the effect of genotype on all other parameters was assessed using one-way ANOVA, with genotype as the independent factor. When significant genotype effects were detected, Bonferroni post hoc tests were performed to identify specific differences between groups. Significance was defined as $p<0.05$. All statistical analyses were performed using the statistical software SPSS 13.01 for Windows.

\section{Results}

\section{Generation of transgenic mice that express the rat homolog of TAG-1 in oligodendrocytes}

Our aim was to test whether the expression of TAG-1 protein by CNS myelinating glia is sufficient to maintain the integrity of the juxtaparanodal domain and rescue the molecular and behavioral phenotype of Tag-1 $1^{-1-}$ mice. For this purpose, we generated mice that are deficient for the murine Tag-1 gene but carry the rat homolog under the $p l p$ gene promoter $\left(\right.$ Tag- $\left.1^{-/-} ; p l p^{\text {Tg(rTag-1 })}\right)$.

Immunohistochemistry was performed in adult cerebellar cryosections of heterozygous (Tag- $1^{+/-}$) and homozygous $\left(\right.$Tag- $1^{-I^{-}}$) mutants as well as Tag-1 ${ }^{-1-} ; p l p^{\text {Tg(rTag-1) }}$ mice to assess proper localization of the transgenic protein (Fig. 1). Double immunostaining using the Olig2 antibody to stain oligodendrocytes and a specific antibody against rTAG-1 (Fig. $1 A-C$ ) revealed the expression of the transgenic protein in Olig $2^{+}$cells and dispersed in the white matter of adult Tag-1 ${ }^{-1-} ; p l p^{T g(r T a g-1)}$ animals (Fig. $1 C)$. As expected, no signal was detected with the anti-rTAG-1 antibody in Tag-1 $1^{+/-}$mice, further supporting its specificity. Subsequent immunohistochemical experiments for the paranodal protein Caspr and rTAG-1 (Fig. 1D-F) showed that the transgenic protein was localized at the juxtaparanodes of myelinated fibers in the cerebellar white matter (Fig. $1 F$ ). WB analysis for TAG-1, myelin proteins (PLP and MBP), and axonal neurofilaments $M$ was performed in separated myelin and axonal fractions from Tag-1 ${ }^{+1-}$, Tag- $1^{-1-}$, Tag-1 $1^{-1-} ; p l p^{\text {Tg(rTag-1)}}$ and Tag- $1^{+/-} ; p l p^{\text {Tg(rTag-1) }}$ brain tissues (Fig. 1G). In Tag- $1^{-1-}$; $p l p^{T g(r T a g-1)}$ mice, transgenic rTAG-1 protein is exclusively detected in the myelin fraction (Fig. 1G; lane 4).

Further experiments were performed in mixed glial cell cultures from P2 Tag- $1^{-1-} ; p l p^{\text {Tg(rTag-1 })}$ mice. Immunocytochemistry on these live cultures after 6 DIV revealed rTAG-1 expression on the surface of Tag- $1^{-1-} ; p l p^{\text {Tg(rTag-1) }}$ oligodendrocytes $\left(\right.$ Olig ${ }^{+}$) (Fig. $1 \mathrm{Ha}$ ). The medium from the cultured cells was subjected to SDS PAGE and immunoblotted for TAG-1. As shown in Figure $1 \mathrm{Hb}$, lane 2, rTAG-1 is released from Tag- ${ }^{-1-} ; \mathrm{plp}^{\text {Tg(rTag-1) }}$ glial cultures. The molecular weight of the released form of TAG-1 is indistinguishable from that of the form detected in brain extracts, as shown previously in dorsal root ganglion and 

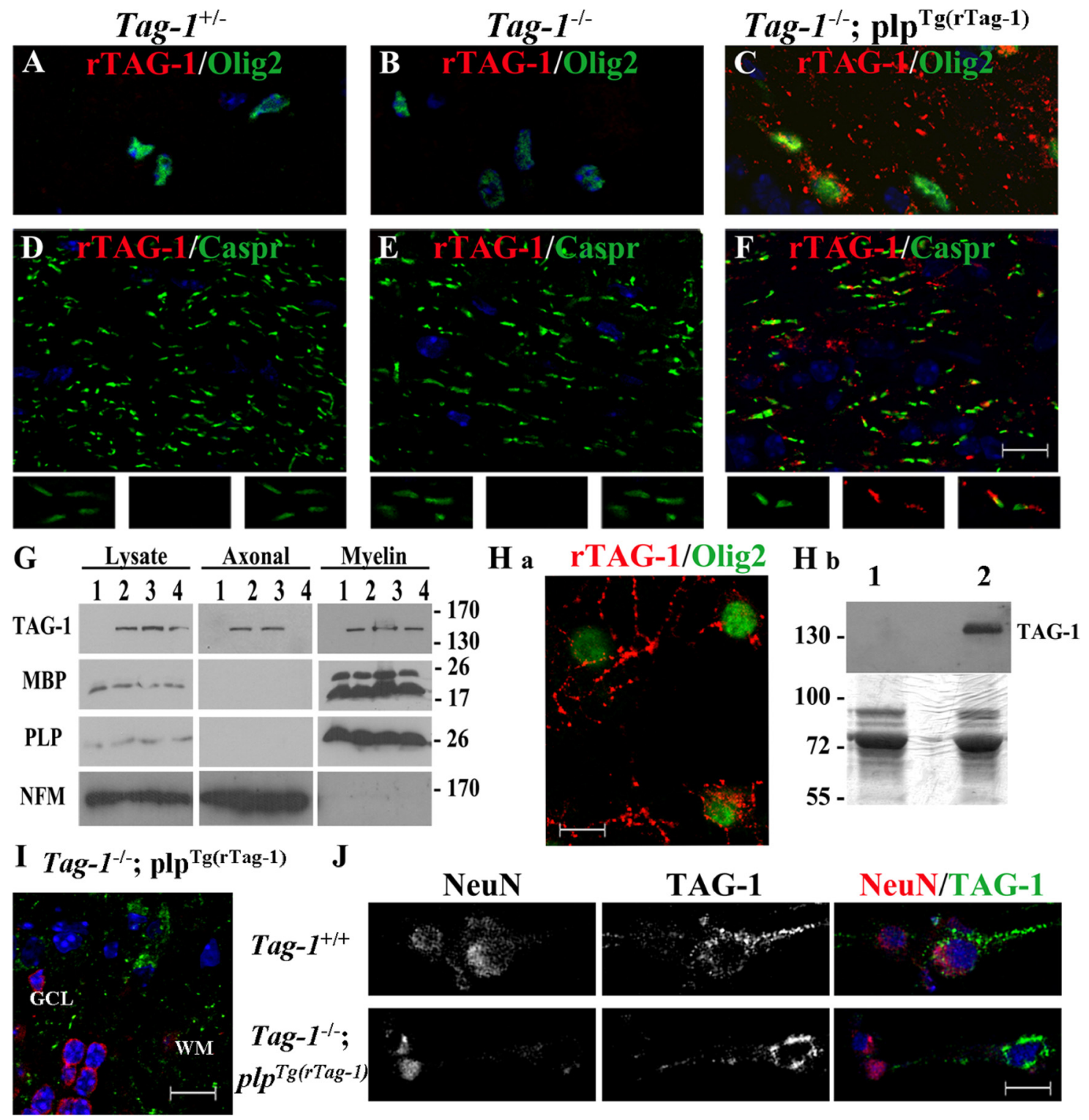

Figure 1. rTAG-1 expression in the CNS of $p / p^{\text {Tg(rTag-1) }}$ mice. $A-F$, Immunohistochemistry in cryosections of adult cerebellar white matter using specific antibodies against $r T A G-1$ in combination

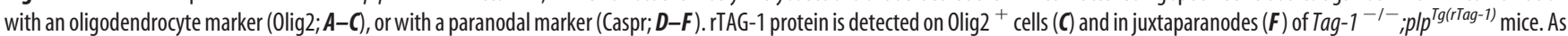
expected, rTAG-1 is not detected in Tag-1 ${ }^{+/-}(\boldsymbol{A}, \boldsymbol{D})$ or Tag-1 ${ }^{-1-}(\boldsymbol{B}, \boldsymbol{E})$ animals. $\mathbf{G}$, Distribution of TAG-1 in axonal and myelin fractions. Two-month-old brain tissues were purified and used for

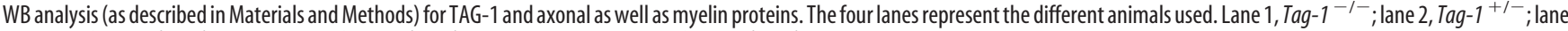

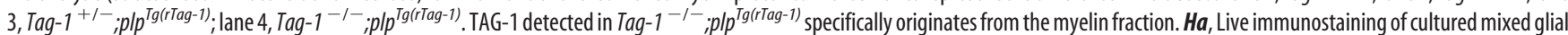
cells from Tag-1 ${ }^{-1-} ;$; $/ p^{\text {Tg(rTag-1) }}$ P2 brains. TAG-1 (red) is found on the cell surface of Olig2 ${ }^{+}$cells (green). $\boldsymbol{H b}$, WB analysis for TAG-1 and Coomassie blue staining of the supernatant medium from

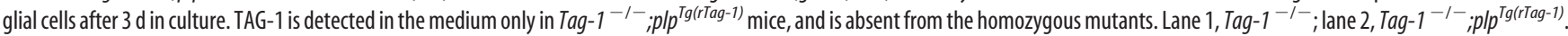
$I$, Immunohistochemistry in cryosections from cerebellum of adult Tag- $1^{-1-} ;$; $/ p^{\text {Tg(rTag-1) }}$ mice for TAG-1 (green) and the neuronal marker NeuN (red). The transgenic protein is clearly not expressed by neurons. J, Immunocytochemistry in P2 dissociated cortices from Tag- $1^{+/+}$and Tag- $1^{-1-} ;$; $/ p^{\text {Tg(rTag-1) }}$ mice with anti-TAG-1 (green) and anti-NeuN (red) antibodies. TAG-1 is expressed by neuronal cells in Tag- ${ }^{+/+}$but not in the transgenic mice. To-Pro3 (blue) is used for the visualization of the nuclei in $\boldsymbol{A}-\boldsymbol{F}, \boldsymbol{I}$, and $\boldsymbol{J}$. Scale bars, $10 \mu \mathrm{m}$. GCL, Granule cell layer; WM, white matter; NFM, neurofilaments $\mathrm{M}$.

spinal cord cell cultures (data not shown) (Karagogeos et al., 1991).

Previous studies have shown that the $p l p$ gene promoter is also active in some neuronal cells (Bongarzone et al., 1999; Miller et al., 2009; Gómez-Casati et al., 2010). To investigate the possibility that transgenic TAG-1 protein may also be expressed in neurons, we performed a series of immunofluorescence experiments in vivo and in vitro. Double immunohistochemistry in adult cerebellar cryosections with a polyclonal a-TAG-1 antibody and the neuron-specific marker, NeuN (Neuronal Nuclei), revealed no sites of colocalization (Fig. 1I). Furthermore, immunocyto- chemistry in P2 dissociated cortices in vitro showed that transgenic rTAG-1 is clearly absent from neuronal cells (Fig. $1 \mathrm{~J}$ ). Our results support the glial-specific expression of TAG-1 in Tag-1 $1^{-1-} ; p p^{\text {Tg(rTag-1) }}$ transgenic mice.

Glial TAG-1 is sufficient to restore the CNS juxtaparanodal phenotype of Tag-1 ${ }^{-1-}$ mice

To examine whether glial TAG-1 is able to restore the clustering of Caspr2 and VGKCs in the juxtaparanodes, we analyzed the molecular organization of the juxtaparanodal region in various CNS areas of Tag- $1^{-1-} ; p l p^{\text {Tg(rTag-1) }}$ mice and compared it with 
the homozygous mutants. We performed a series of immunohistochemical experiments in optic nerve cryosections, using antibodies against paranodal and juxtaparanodal proteins. Immunostaining for Caspr and Caspr2 (Fig. $2 A, C, E$; asterisks in $E$ denote juxtaparanodal staining) revealed a full rescue of the clustering of Caspr2 in Tag- $1^{-1-} ; p l p^{\text {Tg(rTag-1) }}$ mice (Fig. $2 E)$ compared with the mutants in which the localization of the protein is severely disrupted (Fig. 2C). Similar experiments for Caspr and Kv1.2 expression showed that in Tag- $1^{-1-} ; p l p^{\text {Tg(rTag-1 })}$ mice, as in control animals $\left(\right.$ Tag- $\left.1^{+/-}\right)$, Kv1.2 is properly localized in juxtaparanodes, in contrast to its diffused expression in homozygous mutants (Fig. $2 B, D, F$; asterisks in F denote juxtaparanodal staining). After quantification of the percentage of paranodes with properly clustered juxtaparanodes, stained either with Caspr2 (Fig. 2G) or Kv1.2 (Fig. $2 H$ ), we obtained similar numbers for Tag-1 ${ }^{-1-}$; $p l p^{\text {Tg(rTag-1) }}$ and Tag- $1^{+/-}$littermates (no statistically significant difference), although the percentage was significantly lower in Tag- $1^{-1-}$ mice (Student's $t$ test, Tag- $1^{+/-}$vs Tag- $1^{-1-}, p<0.05$; Tag- $1^{-1-}$ vs Tag- $1^{-1-}$; $p l p^{\text {Tg(rTag-1) }}, p<0.05$ for Caspr2 and Kv1.2; in Fig. $2 G, H,{ }^{* * *}$ represents $p<0.05$ ).

In addition to the optic nerve, we examined other CNS areas such as the hippocampus, entorhinal cortex, corpus callosum, and cerebellum (supplemental Figs. 2, 3, available at www.jneurosci.org as supplemental material). The molecular restoration of the juxtaparanodes was evident in all CNS areas tested. These results indicate that glial TAG-1 is sufficient for the clustering of VGKCs and Caspr2 in the juxtaparanodal region of CNS myelinated fibers.

The PLP protein is predominantly expressed in oligodendrocytes but plp gene products have also been detected in Schwann cells (Puckett et al., 1987; Wight et al., 1993, 2007; Griffiths et al., 1995; Garbern et al., 1997). Immunostaining in live, P4, cultured Schwann cells from Tag$1^{-1-} ; p l p^{T g(r T a g-1)}$ mice after 4 DIV showed that rTAG-1 is expressed on the cell surface of Schwann cells in a similar pattern as was previously reported for normal rats (data not shown) (Traka et al., 2002). We also tested the expression of rTAG-1 in the sciatic nerve from Tag- $1^{-1-}$; $p l p^{T g(r T a g-1)}$ mice. Western blot analysis revealed high expression of the transgene in two of four lines generated (supplemental Fig. 4A, available at www.jneurosci.org as supplemental material). Immunohistochemistry in teased fibers for Caspr and rTAG-1 revealed the expression of the transgene in the two positive lines, where it was found localized in paranodes toward the nodes (supplemental Fig. $4 \mathrm{Bi}$, available at
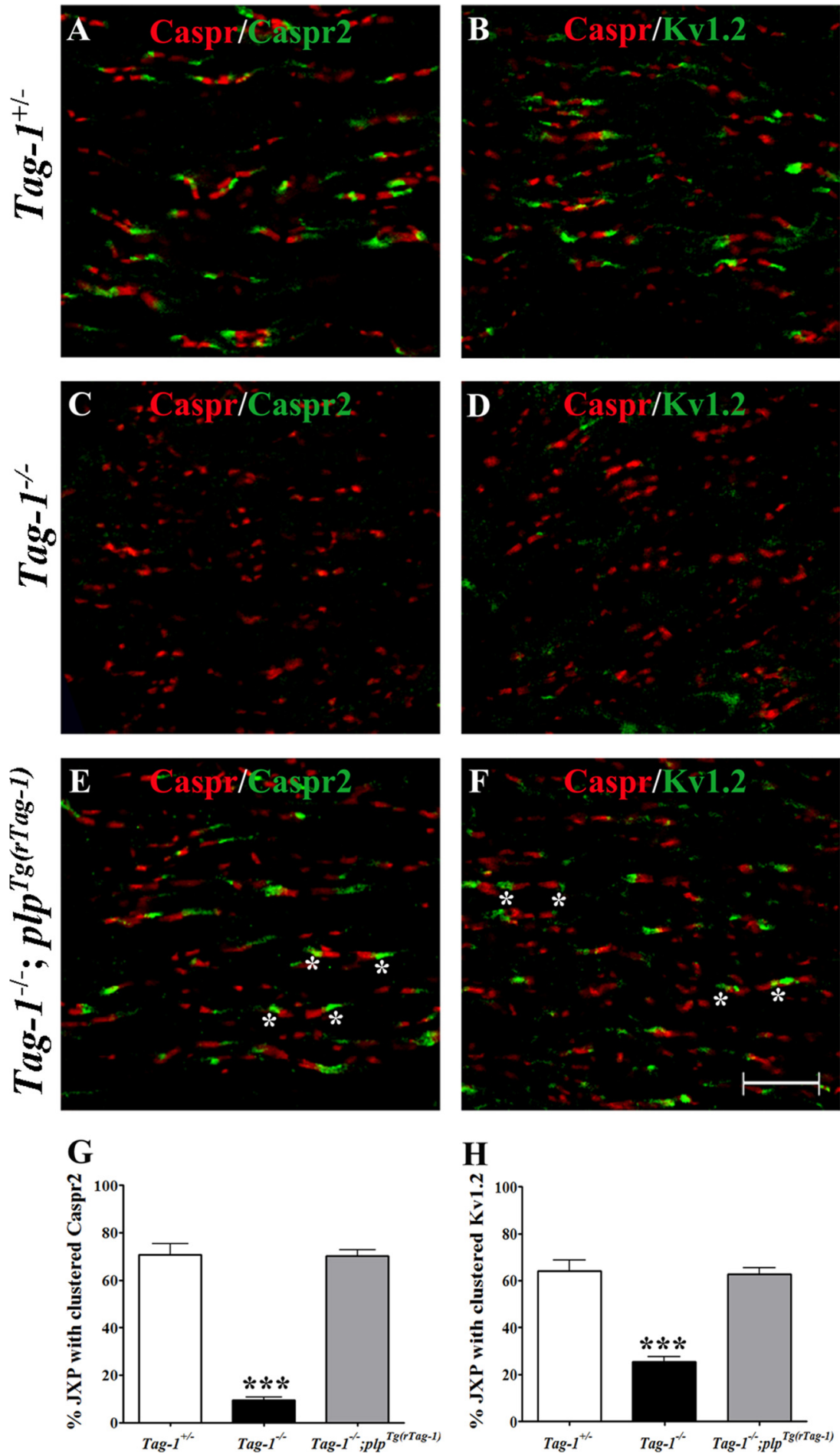

Figure 2. Rescue of the juxtaparanodal complex by glial TAG-1 expression in the optic nerve. $A-F$, Immunohistochemistry of longitudinal optic nerve cryosections for Caspr and the juxtaparanodal proteins Caspr2 and Kv1.2. Caspr2 and Kv1.2 are normally clustered in juxtaparanodes of $\operatorname{Tag}_{-1}{ }^{+-}(\boldsymbol{A}, \boldsymbol{B})$ and $\operatorname{Tag}_{-1}^{-1-} ;$; $/ p^{\text {Tg(rTag-1) }}(\boldsymbol{E}, \boldsymbol{F}$; asterisks denote juxtaparanodal staining) mice, whereas their localization is disrupted in the $\operatorname{Tag} 1^{-1-}$ optic nerve $(C, D) . G, H$, Quantification of the percentage of paranodes stained with Caspr having

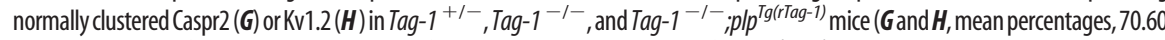

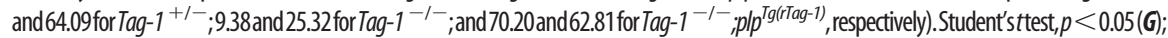

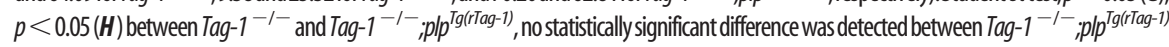
and normal littermates, $n=3$ of each genotype. Bar graphs depictmean \pm SEM. ${ }^{* * *} p<0.05$.JXP, Juxtaparanodes. Scale bar, $10 \mu \mathrm{m}$.

www.jneurosci.org as supplemental material). In these lines, we further examined the localization of rTAG-1 compared with a glial paranodal marker, NF155. We observed that both proteins are localized at paranodes, but are found in different membrane 


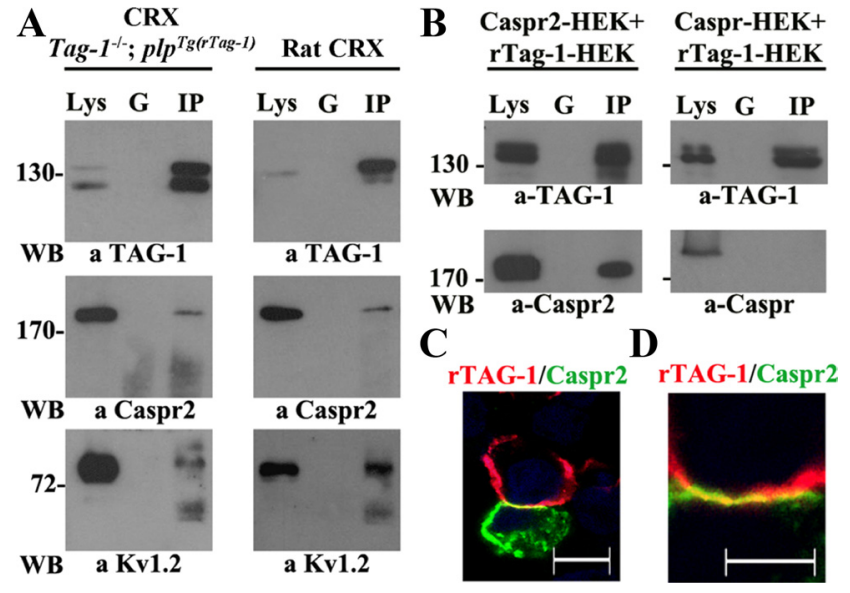

Figure 3. $\quad A, C 0-I P$ analysis from adult rat and mouse $\operatorname{Tag}^{-1^{-1-}} ;$; $/ p^{T g(\text { rTag-1) }}$ cortex using anti (a)-rTAG-1 antibody. WB for Caspr2 and Kv1.2 reveals that rat TAG-1 expressed by oligodendrocytes in $T a g-1^{-1-} ; p_{1} p^{\text {Tg(rTag-1) }}$ mice physically interacts with the two proteins. $\boldsymbol{B}$, HEK293 cells expressing rTAG-1 were mixed with cells expressing Caspr2 or cells expressing Caspr (used as a negative control), and cultured together for $24 \mathrm{~h}$. The lysates (Lys) were initially precleared with protein $G$ beads $(G)$ and then subjected to IP with anti-rTAG-1 antibody. WB analysis for TAG-1 and Caspr2 or Caspr revealed a direct interaction between rTAG-1 and Caspr2 expressed by different cells. $\boldsymbol{C}, \boldsymbol{D}$, Immunostaining of the mixed rTAG-1 and Caspr2 population shows that there is colocalization of the two proteins at the contact site. To-Pro 3 (blue) is used for the staining of the nuclei. $\boldsymbol{D}$, Higher magnification of the two proteins contact site shown in C. Scale bars: $C, 10 \mu \mathrm{m} ; \mathbf{D}, 5 \mu \mathrm{m}$.

compartments of the glial cell, as shown in supplemental Figure $4 \mathrm{Bii}$, inset (available at www.jneurosci.org as supplemental material), whereas double immunostaining for rTAG-1 and the nodal protein NF186 revealed that the transgenic protein was found next to the node (supplemental Fig. 4 Biii, available at www.jneurosci.org as supplemental material). We further examined the clustering of the juxtaparanodal proteins Caspr2 and Kv1.2 in sciatic nerves by immunohistochemistry against Caspr and each of those proteins (supplemental Fig. 4C, available at www.jneurosci.org as supplemental material). Teased fibers from sciatic nerves of Tag-1 $1^{-1-} ; p l p^{\text {Tg(rTag-1) }}$ mice show dramatically decreased and diffused Caspr2 and Kv1.2 clustering, resembling the phenotype of Tag-1 $1^{-1-}$ mice.

\section{Glial TAG-1 physically interacts with Caspr2 and VGKCs}

Each region of the myelinated fibers is characterized by the formation of specific complexes between proteins of the axon and the glial cell membrane. TAG-1 has previously been found to interact directly with Caspr2 and the VGKC subunits in juxtaparanodes, and this interaction is crucial for the proper formation of this region (Poliak et al., 2003; Traka et al., 2003; Tzimourakas et al., 2007). Since our data demonstrate that glial TAG-1 is sufficient for the proper clustering of Caspr2 and VGKCs (Fig. 2; supplemental Figs. 2 and 3, available at www. jneurosci.org as supplemental material), we further analyzed whether it can directly interact with them in the absence of axonal TAG-1. Co-IP experiments were performed in cortical tissue from Tag-1 ${ }^{-1-} ; p p^{\text {Tg(rTag-1) }}$ mice and normal rats (used as positive control), using the anti-rTAG-1 antibody. Western blot analysis for TAG-1, Caspr2, and Kv1.2 revealed that glial TAG-1 is found in the same complex with both axonal proteins of juxtaparanodes (Fig. 3A). TAG-1 expressed by the glial membrane in our transgenic lines could directly interact with Caspr2 on the axon. Alternatively, released TAG-1 from glial cells could medi- ate the binding to Caspr2 alone or facilitate the binding of TAG-1 expressed on the glial membrane to axonal Caspr2.

To shed light on these interactions, we used an in vitro system, where we cultured cells expressing Caspr2 on top of a monolayer of HEK293 cells expressing rTAG-1 and vice versa. The two cell populations were left in culture for $24 \mathrm{~h}$. Then lysates were subjected to IP with the anti-rTAG-1 antibody. To test the specificity of this interaction, cells expressing Caspr, which does not bind to TAG-1, were used as a negative control. Immunoblot for Caspr2 and Caspr revealed an interaction only between Caspr2 and rTAG-1 (Fig. 3B). Immunostaining of the mixed cultures of cells expressing Caspr2 and cells expressing TAG-1 revealed single positive cells (TAG-1 or Caspr2) and showed colocalization of both proteins in contact sites of opposed cell membranes (Fig. 3C). We further tested whether the soluble form of rTAG-1, released by Tag-1 ${ }^{-1-}$; $p l p^{T g(r T a g-1)}$ glial cultures, is able to bind on the surface of cells expressing Caspr2; we were unable to detect binding of soluble rTAG-1 on Caspr2 transfected or untransfected cells (data not shown). Our data suggest that TAG-1 expressed by glial cells is able to interact with Caspr2 only when both proteins are expressed on opposing cell surfaces.

TAG-1 expressed by oligodendrocytes is able to restore the myelin and axonal defects in the optic nerves of Tag- $^{-1-}$ mice

The study by Chatzopoulou et al. (2008) showed a small hypomyelination, a significant loss of small caliber axons, and an increase in medium and large caliber retinal ganglion cell (RGC) axons in optic nerves of Tag-1 $1^{-1-}$ mice compared with agematched normal animals. We tested the possibility that TAG-1, expressed specifically from oligodendrocytes, is sufficient to reverse the myelination and axonal phenotype of the homozygous mutant mice. We performed ultrastructural analysis on crosssectioned optic nerves from adult Tag- $1^{+/+}$, Tag- $1^{-1-}$, and Tag$1^{-1-} ; p l p^{T g(r \text { Tag-1) }}$ animals. The area of the fiber with and without the myelin sheath was measured as shown in Figure $4 A$ (dashed lines), followed by calculation of the diameter and subsequently of the $g$ ratio. As shown in Figure $4 B$, there is a small but statistically significant decrease in the $g$ ratio of Tag-1 $1^{-1-} ; p l p^{\text {Tg(rTag-1) }}$ optic nerve compared with the homozygous mutants (Student's $t$ test, $p<0.05, \mathrm{~g}_{0}=0.7010$ for Tag- ${ }^{-1-} ; p l p^{\text {Tg(rTag-1) }}, \mathrm{g}_{0}=0.7353$ for $\operatorname{Tag} 1^{-/-}$), suggesting that the expression of glial TAG-1 has positively affected the myelin sheath thickness. The g ratio of transgenic optic nerves resembles that of normal material from three age-matched mice (data not shown) $\left(\mathrm{g}_{0}=0.7077\right.$ for $\operatorname{Tag}-1^{+/+}$).

In addition, we analyzed the distribution of RGC axons according to their caliber in Tag-1 ${ }^{+/+}, \operatorname{Tag}^{-/-}$, and $\mathrm{Tag}-1^{-/-}$; $p l p^{T g(r \text { Tag-1 })}$ mice. As shown in Figure $4, C$ and $D$, more small caliber axons are present in the optic nerve from $\mathrm{Tag}-1^{-1-}$; $p l p^{T g(r \text { Tag-1 })}$ mice, compared with the Tag $1^{-1-}$ material. Quantification of the number of axons according to their diameter revealed a significant increase in the pool of small caliber axons $(<500 \mathrm{~nm})$, as well as a small but significant decrease in medium and large caliber axons in Tag-1 $1^{-1-} ; p l p^{\text {Tg(rTag-1) }}$ optic nerves compared with age-matched Tag- $1^{-1-}$ animals (Fig. $4 E$ ). No statistically significant difference was observed between Tag- $1^{-1}$ -;plp $p^{\text {Tg(rTag-1) }}$ and Tag-1 ${ }^{+/+}$mice. The above results indicate that glial TAG-1 positively regulates and favors the small caliber axons versus medium diameter axons in the optic nerve in the absence of the axolemmal TAG-1. 
Behavioral analysis of Tag-1 ${ }^{-/-}$; $p l p^{T g(r T a g-1)}$ mice reveals rescue of the defects detected in Tag-1 ${ }^{-/-}$animals We have previously described the behavioral phenotype of Tag-1 ${ }^{-/-}$mice, which display impairments in learning and memory as well as in motor coordination (Savvaki et al., 2008). Our aim in the present study was to analyze the behavior of Tag-1 $1^{-1-} ; p l p^{\text {Tg(rTag-1) }}$ mice compared with the homozygous mutants and normal animals. We used the MWM (cued and hidden versions) and novel-object recognition tests to study learning and memory parameters. For the study of motor coordination and balance, mice were subjected to the rotarod test and footprint analysis.

As expected (Savvaki et al., 2008), all mice, regardless of their genotype, performed similarly in the cued version of the MWM task and reduced their latency to reach the visible platform across the $3 \mathrm{~d}$ of training (data not shown) $\left(F_{(2,42)}=\right.$ 68.992, $p<0.001)$.

In the hidden version of MWM, all mice, regardless of their genotype, appeared to swim normally and showed no difficulty in mounting the hidden platform provided. A significant effect of day was observed on the latency to find the hidden platform $\left(F_{(3,63)}=20.604, p<\right.$ 0.001) (Fig. 5A), since mice of all three genotypes progressively decreased their latency across the $4 \mathrm{~d}$ of training. Moreover, a significant genotype effect was observed on latency $\left(F_{(2,21)}=5.651, p=0.011\right)$ as both Tag-1 $1^{-1-} ; p l p^{\operatorname{Tg}(r \operatorname{Tag}-1)}$ and Tag-1 $1^{+1+}$ mice learned the task more efficiently than the Tag-1 ${ }^{-1-}$ age-matched animals (Bonferroni post hoc test, $p=0.016$ for the comparison of Tag- $1^{-1-}$; $p l p^{T g(r T a g-1)}$ vs Tag- $1^{-1-}$ and $p=0.044$ for the comparison of Tag $-1^{+/+}$vs Tag- $1^{-/-}$). No difference was observed in learning of the MWM between Tag- $1^{-1-} ; p l p^{\text {Tg(rTag-1) }}$ and Tag- $1^{+/+}$mice. Finally, no difference was observed in the animals' swim speed in both versions of the MWM task (data not shown).

In the long-term memory probe trial ( $24 \mathrm{~h}$ after the last training trial), statistical analysis revealed a significant quadrant $\times$ genotype interaction on the time spent in the target and opposite quadrants $\left(F_{(1,47)}=6.591, p=0.003\right)$ (Fig. 5BI). Further analysis revealed that both Tag- $1^{-1-} ;$ plp $p^{\text {Tg(rTag-1) }}$ and Tag- $1^{+/+}$animals showed a preference for the target quadrant ( post hoc, $p=0.001$ for both groups of animals) (Fig. $5 B$ ), whereas Tag- $1^{-1-}$ mice showed no quadrant preference ( post hoc, $p=0.938$ ) (Fig. $5 B$ ). Thus, both spatial learning and long-term memory deficits exhibited by the $\mathrm{Tag}-1^{-1-}$ mice were restored in $\mathrm{Tag}-1^{-1-}$; $p l p^{\operatorname{Tg}(r \text { Tag- } 1)}$ animals to levels comparable to that of Tag- $1^{+/+}$ mice.

Mice were also tested for their ability to discriminate between a novel object and a familiar one, which was presented to the animals shortly before the novel one (novel-object recognition test). Interestingly, a significant genotype effect was observed on the discrimination index $\left(F_{(2,23)}=18.118, p<0.001\right)$ (Fig. $5 C$ ), as both $\operatorname{Tag}-1^{-1-} ; p l p^{\text {Tg(rTag-1) }}$ and Tag- $1^{+1+}$ mice appeared to perform better than Tag-1 $1^{-1-}$ animals in this task ( post hoc $p<$
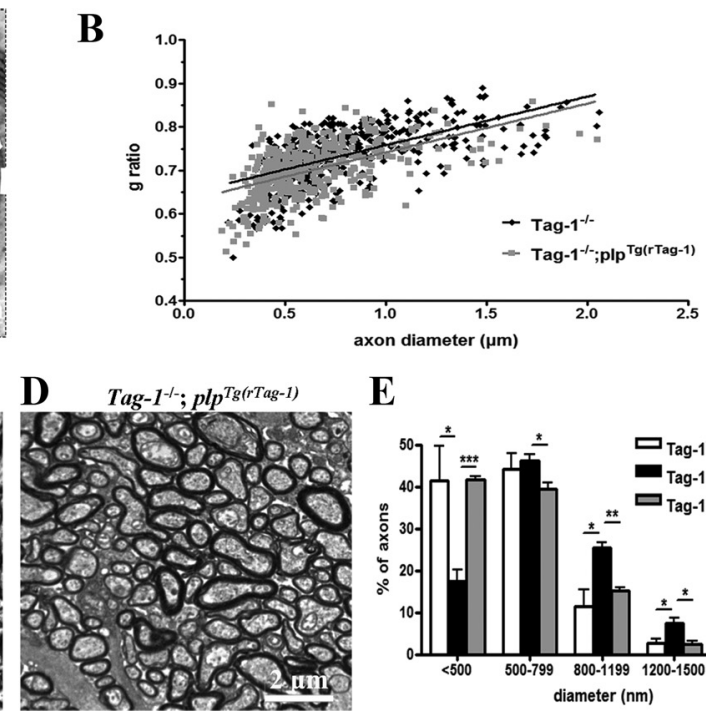

E

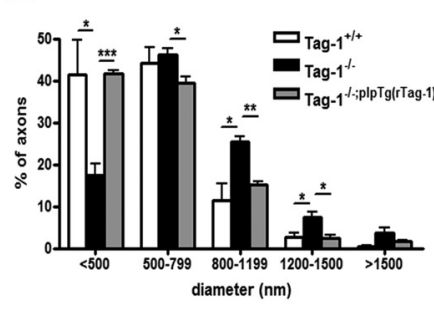

Figure 4. Ultrastructural analysis of optic nerves from $\operatorname{Tag}_{-1}^{-1-}$ and $\operatorname{Tag}-1^{-1-} ;$ plp ${ }^{\operatorname{Tg}(\text { rTag-1) }}$ mice. $A$, Image from the electron microscope of a cross-sectioned optic nerve from a normal mouse. The dashed lines indicate the areas measured for the calculation the diameter of the axon with and without the myelin sheath and subsequently the $g$ ratio of the fibers. $B, G$ ratio diagram for the

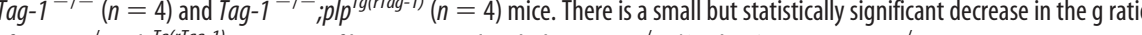
( the homozygous mutants phenotype ( $>200$ axons measured for each mouse, unpaired Student's $t$ test, ${ }^{* * *} p<0.001,{ }^{* *} p<$

0.001 for either comparison of $\operatorname{Tag}-1^{-1-} ; p l p^{\text {Tg(rTag-1) }}$ vs Tag$1^{-1-}$ or $\operatorname{Tag}-1^{+/+}$vs $\left.\operatorname{Tag}-1^{-1-}\right)$. The discrimination ability of Tag- $1^{-1-} ; p l p^{\text {Tg(rTag-1) }}$ animals was indistinguishable of that of Tag- $1^{+/+}$mice. Both Tag- $1^{-1-} ; p l p^{\text {Tg(rTag-1) }}$ and Tag- $1^{+/+}$mice were able to discriminate between the familiar and novel object and spent more time exploring the novel one, compared with the familiar one. On the contrary, the homozygous mutant mice spent the same amount of time exploring the familiar and the novel object. Tag-1 ${ }^{-1-}$ animals showed no recognition memory, whereas Tag-1 ${ }^{-1-} ; p l p^{T g(r T a g-1)}$ mice had a clear preference for novel objects as do Tag- $1^{+/+}$animals.

The rotarod test was used to investigate motor coordination behavior. A significant day of training $\times$ genotype interaction was observed on the latency before falling off during the training phase $\left(F_{(2,42)}=3.143, p=0.024\right)$ (Fig. 5DI). Further analysis revealed that both Tag-1 ${ }^{-1-} ; p l p^{\text {Tg(rTag-1) }}$ and Tag- $1^{+/+}$mice stayed on the rotarod longer compared with Tag-1 $1^{-1-}$ animals during the second ( $p o s t$ hoc tests, $p<0.001$ and $p=0.004$, respectively) and the third ( $p o s t$ hoc tests, $p<0.001$ for both comparisons) day of training. Furthermore, a significant genotype effect was identified on the latency to fall during testing both at 20 and $32 \mathrm{rpm}$ speed, as both Tag-1 ${ }^{-1-} ; p l p^{\text {Tg(rTag-1) }}$ and Tag$1^{+/+}$mice stayed on the rotarod longer compared with the Tag$1^{-1-}$ animals $\left(20 \mathrm{rpm}, F_{(2,23)}=42.502, p<0.001\right.$, post hoc, $p<$ 0.001 for both comparisons; $32 \mathrm{rpm}, F_{(2,23)}=57.745, p<0.001$, post hoc, $p<0.001$ for both comparisons) (Fig. 5DII). Based on all rotarod parameters analyzed, Tag- $1^{-1-} ; p l p^{\text {Tg(rTag-1) }}$ mice outperformed Tag- $1^{-1-}$ animals in their ability for motor coordination and balance and had a similar performance to Tag- $1^{+/+}$mice. 
$\mathbf{A}$

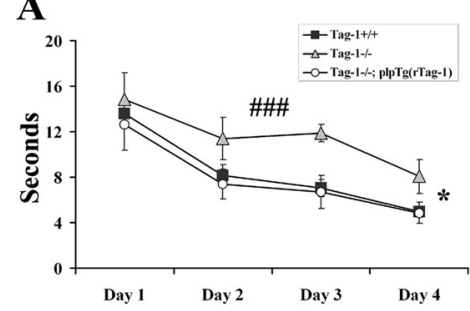

B
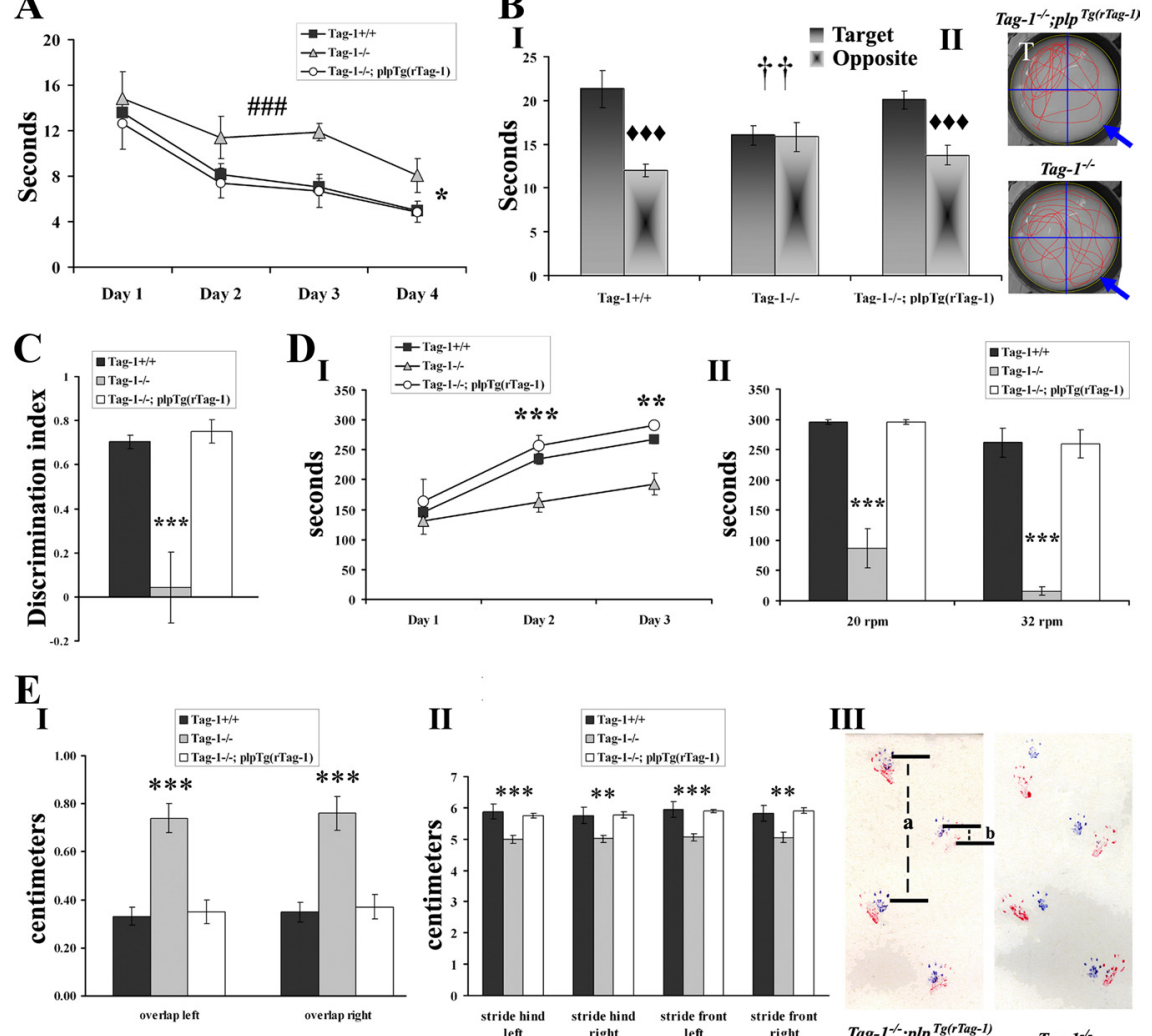

III

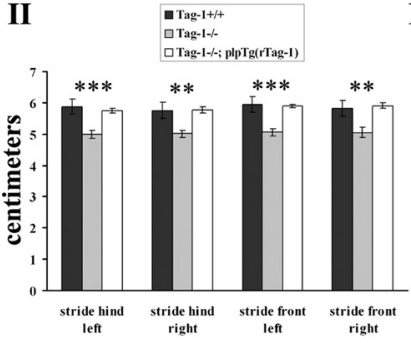

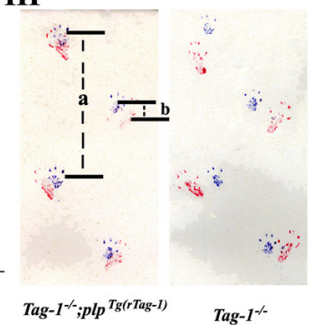

Figure 5. Analysis of the behavioral phenotype of $T a g-1^{-1-} ;$; $/ p^{\text {Tg(rTag-1) }}$ compared with the $T a g-1^{-/-}$and $T a g-1^{+/+}$mice. $A$, Acquisition of the hidden version of the MWM. Mean latency \pm SEM across the $4 \mathrm{~d}$ of the acquisition phase. Note that Tag-1 ${ }^{-1-} ;$; $/ p^{\text {Tg(rTag-1) }}$ mice reached the hidden platform faster than the $\operatorname{Tag}-1^{-1-}$ mice and with the same latency as Tag $-1^{+/+}$ animals. Genotype effect, ${ }^{*} p<0.05$; day of training effect, ${ }^{\# \# \#} p<0.001$. B, Long term memory probe trial (performed $24 \mathrm{~h}$ after the last training trial) of the hidden version of the MWM. $B$ I, Time spent in the target and opposite quadrants during the probe trial. Bar graphs depict mean \pm SEM. Note that both $T a g-1^{-1-} ;$ plp Tg(rTag-1) and Tag- $1^{+/+}$mice showed a preference for the target quadrant. BII, Representative paths followed by Tag- $1^{-1-} ;$ plp Tg(rTag-1) $^{\text {and } T a g-1^{-1-}}$ mice during the probe trial. T marks the quadrant where the platform was located during training and the arrow the starting position in the probe trial. Genotype $X$ quadrant interaction, ${ }^{\dagger \dagger} p<0.01$; quadrant effect, $\bullet p<0.05$. C, Performance in the novel-object recognition task, expressed as the discrimination index. Bar graphs depict mean \pm SEM. Tag- $1^{-1-} ;$ plp $p^{\text {Tg(rTag-1) }}$ and Tag- $1^{+/+}$mice spent more time exploring the novel than the familiar object, as expected; in contrast, $\mathrm{Tag}_{-1}^{-1-}$ mice did not show a preference for the novel object (genotype effect, ${ }^{* * *} p<0.001$ ). D, Motor coordination as assessed by the rotarod test. $\boldsymbol{D I}$, Latency to fall across the $3 \mathrm{~d}$ of training. Mean latency \pm SEM. DII, Latency to fall during the testing phase. Bar graphs depict mean \pm SEM. Tag $-1^{-1-}$; $p / p^{\text {Tg(rTag-1) }}$ and Tag- $1^{+/+}$mice stayed on the rotarod for a longer time before falling off compared with the Tag- $1^{-1-}$ mice on the second and third days of training as well as during testing at 20 and $32 \mathrm{rpm}$ speed $\left({ }^{* *} p<0.01 ;{ }^{* * *} p<0.001\right)$. E, Footprint analysis. El, Overlap width, for both right and left limbs, was significantly smaller in the Tag- $1^{-1-} ;$; plp $p^{\text {T(rTag-1) }}$ and Tag- $1^{+/+}$ mice compared with the $\mathrm{Tag}-1^{-1-}$ mice $\left({ }^{* * *} p<0.001\right)$. Ell, Stride length, for both right and left limbs; the front and hind stride measurements were significantly larger in the Tag- $1^{-1-} ;$; $/ p^{T g(r T a g-1)}$ and $T a g-1^{+/+}$mice than those in the $\operatorname{Tag}-^{-1-}$ mice $\left({ }^{* *} p<0.01 ;{ }^{* * *} p<0.001\right)$. Bars represent mean \pm SEM. EIII, Representative photograph of footprints from a Tag- $1^{-1-}$; plp $p^{\text {Tg(rTag-1) }}$ and a Tag- $1^{-1-}$ mice animal, indicating the parameters measured: a, Stride length; b, overlap width.

To further explore the motor behavior of $\mathrm{Tag}^{-1^{-1-}}$; $p l p^{\operatorname{Tg}\left(r_{\text {Tag-1 }}\right)}$ mice, footprint analysis was performed and three parameters were analyzed: overlap width, forelimb stride length, and hindlimb stride length for the left and right limbs separately. Statistical analyses revealed a significant genotype effect on all parameters measured: compared with the Tag-1 $1^{-1-}$ animals, both Tag-1 ${ }^{-1-} ; p l p^{T g(r T a g-1)}$ and Tag- $1^{+/+}$mice had smaller left and right overlap widths (left, $F_{(2,23)}=24.225, p<0.001$, post hoc $p<0.001$ for both comparisons; right, $F_{(2,23)}=20.291, p<$ 0.001 , post hoc $p<0.001$ for both comparisons) (Fig. 5EI) and larger hind and front paw strides (left hind paw, $F_{(2,23)}=9.949$, $p=0.001$, post hoc, $p<0.01$ for both comparisons; right hind paw, $F_{(2,23)}=7.063, p=0.005$, post hoc, $p<0.05$ for both comparisons; left front paw, $F_{(2,23)}=10.683, p=0.001$, post hoc, $p<$
0.005 for both comparisons; right front paw, $F_{(2,23)}=7.647, p=0.003$, post hoc, $p<0.05$ for both comparisons) (Fig. $5 E I I)$. Overall, the motor behavior of Tag$1^{-1-} ; p l p^{T g(r T a g-1)}$ animals, as assessed by the footprint analysis (Fig. 5EIII), was superior to that of Tag-1 ${ }^{-1-}$ mice and similar to that of Tag- $1^{+/+}$mice.

\section{Discussion}

Glial TAG-1 is sufficient for the formation of the juxtaparanodal complex in the CNS

In the present study, we show that glial TAG-1, in the absence of axonal TAG-1, fully rescues the juxtaparanodal phenotype of Tag- $1^{-1-}$ mice in the CNS. We generated transgenic mice that exclusively express TAG-1 by oligodendrocytes under the $p l p$ gene promoter $\left(\right.$ Tag- $1^{-1-}$; $\left.p l p^{T g(r T a g-1)}\right)$. We found that in these mice, Caspr2 and VGKCs are properly localized in myelinated fibers, indicating intact juxtaparanodal regions. Biochemical and immunohistochemical experiments confirm the absence of TAG-1 protein in the axons of Tag- $1^{-1-} ; p l p^{\text {Tg(rTag-1) }}$ mice and reveal that transgenic glial rTAG-1 forms a complex with the juxtaparanodal proteins Caspr2 and Kv1.2. Transgenic protein is detected on the surface of oligodendrocytes in culture as well as released in the supernatant medium. The physical interaction of glial rTAG-1 with Caspr 2 could result from a direct trans interaction; alternatively, rTAG-1 released by oligodendrocytes may play a role in this binding. When Caspr2-expressing cells are cultured on top of rTAG-1-transfected cells and vice versa, the two proteins are detected on the cell surface, colocalize at contact sites, and coimmunoprecipitate, thus supporting a direct trans interaction; however, we cannot exclude the possibility that released TAG-1 may be involved in this complex. A direct trans interaction is unexpected in the light of previous results (Traka et al., 2003). However, this was the first time that membrane TAG-1 and Caspr 2 were tested and shown to interact in trans, as the lack of trans interaction seen in previous studies involved Caspr 2 and soluble TAG-1 in the form of an Fc chimera. Consistent with this, we were not able to detect binding of the transgenic protein released by glial cells in vitro to Caspr2expressing cells. These observations may indicate the need of the released form for a partner anchored on the glial cell, which can be either TAG-1 itself or a yet unidentified molecule.

In the wild-type situation, a trans homophilic binding of TAG-1 may be the first step in the formation of the juxtaparanodal complex, followed by a cis binding of axonal TAG-1 to axonal Caspr2 (Poliak et al., 2003; Traka et al., 2003; Tzimourakas et al., 2007). The results presented here suggest that the cis interaction of TAG-1 and Caspr2 on the axon may not be a prerequisite 
for the juxtaparanodal complex assembly. A possible role of axonal TAG-1 could be in facilitating and stabilizing the axoglial interaction between axonal Caspr 2 and TAG-1 expressed by the oligodendrocyte. We propose that in the transgenic situation, this putative role of axonal TAG-1 may be undertaken by the released protein.

In addition to the CNS, we also examined the expression of rTAG-1 in transgenic mice by myelinating glial cells in the peripheral nervous system (PNS). In teased sciatic nerve fibers of Tag-1 $1^{-1-} ; p l p^{T g(r T a g-1)}$ mice, rTAG-1 is highly expressed but ectopically localized in the outer paranodal membrane toward the node of Ranvier. This ectopic expression probably precludes the restoration of the juxtaparanodal complex in the PNS and may suggest a divergent mechanism of juxtaparanodal region formation in the PNS. The difference between CNS and PNS may arise either due to technical issues of the transgene expression in the PNS or due to a requirement of TAG-1 on axons to localize glial TAG-1 at PNS juxtaparanodes.

\section{Glial TAG-1 is able to regulate the myelination level and the axonal distribution of RGC axons}

A previous study revealed a small hypomyelination and a significant loss of small caliber axons in Tag- $1^{-1-}$ mice compared with normal littermates (Chatzopoulou et al., 2008). Here we show that rTAG-1 expressed exclusively by oligodendrocytes in Tag$1^{-/-}$mice is sufficient to rescue these phenotypes in the CNS. G ratio, an indicator of the myelin sheath thickness, is restored to normal levels in Tag- $1^{-1-} ; p l p^{T g(r T a g-1)}$ mice, suggesting that glial TAG-1 positively regulates the myelination process in the CNS. Therefore, TAG-1 may be added to the list of a small number of proteins (PDGF $\alpha$, WAVE-1, NogoA, neuregulin 1 nectin-like 1) that affect the level of myelination in CNS fibers apart from those that influence the myelin structure such as MBP and PLP (Popko et al., 1987; Griffiths et al., 1998; Fruttiger et al., 1999; Kim et al., 2006; Brinkmann et al., 2008; Park et al., 2008; Pernet et al., 2008).

The loss of small caliber axons observed in Tag- $1^{-1-}$ mice is a common feature in various types of metabolic optic neuropathies in humans, where degeneration of the optic nerve takes place (Saadati et al., 1998; Carelli et al., 2002; Sadun, 2002; Zoumalan et al., 2005). The small caliber axons in the optic nerve fire at rapid rates and are thinly myelinated. These characteristics could make them more susceptible to loss than larger, more extensively myelinated axons in optic neuropathies. In mice, TAG-1 is the only molecule recognized so far, which is essential for the maintenance of the number of small caliber axons and positively regulates them in the visual system. The results presented here suggest that the expression of TAG-1 in oligodendrocytes in transgenic mice may act as an extrinsic signal to allow maintenance of RGC axons.

\section{Glial TAG-1 can rescue the behavioral phenotype of Tag-1 $^{-/-}$ mice}

We have demonstrated in the past that Tag- $1^{-1-}$ mice display behavioral impairments compared with Tag-1 $1^{+/+}$animals. More specifically, Tag-1 ${ }^{-1-}$ mice underperformed in the MWM and novel-object recognition tests, and showed abnormal motor coordination (Savvaki et al., 2008). In this report, we clearly show that TAG-1 expression exclusively by glial cells is sufficient to fully rescue the behavioral phenotype of homozygous mutants.

Tag- $1^{-1-} ; p l p^{\text {Tg(rTag-1) }}$, Tag- $1^{-1-}$, and Tag- $1^{+/+}$mice were subjected to a battery of tests used for memory and learning abilities, i.e., MWM and novel-object recognition, as well as for motor coordination, i.e., rotarod and footprint analysis. MWM and novel-object recognition tasks were used for testing spatial and recognition learning and memory abilities, respectively. In both tasks, Tag-1 ${ }^{-1-} ; p p^{\text {Tg(rTag-1) }}$ mice displayed no defects in their ability to learn, resembling the performance of Tag-1 ${ }^{+/+}$ mice. MWM is a hippocampal-dependent test, whereas novelobject recognition depends on the rhinal cortices (Parron and Save, 2004; Dere et al., 2007). Previous studies have shown that VGKC currents play an important role in the functional remodeling of the neuronal network that is necessary for long-term memory. More specifically, antisense oligodeoxyribonucleotides against Kv1.1, impaired associative memory in rodents (Meiri et al., 1997). Expression of glial TAG-1 in Tag-1 $1^{-1-} ; p l p^{\text {Tg(rTag-1) }}$ mice restores the juxtaparanodal localization of VGKCs and Caspr2 in the hippocampus and the entorhinal cortex, which could account for the rescued cognitive phenotype of those mice. However, we cannot exclude the possibility that the learning and memory defects in Tag- $1^{-1-}$ mice may arise from developmental functions of the protein in the limbic system.

The motor coordination and gait abnormalities, previously described in Tag-1 ${ }^{-I-}$ mice, could be related to the abnormal distribution of Kv1.1/1.2 channels in various CNS areas (Traka et al., 2003; Savvaki et al., 2008). Impaired motor activity and gait ataxia have previously been correlated with cerebellar dysfunction in other mouse models with cerebellar defects (Oliver et al., 2007). Here we show that exclusive expression of glial TAG-1 in Tag- $1^{-1-} ; p l p^{\text {Tg(rTag- } 1)}$ animals results in normal gait coordination and motor organization (as determined by the rotarod test and footprint analysis) that could be attributed to the proper juxtaparanodal formation in the cerebellum among other CNS areas.

The integrity of myelinated fibers is crucial for their proper function. In demyelinating diseases of the CNS such as multiple sclerosis, the regions around the node of Ranvier are susceptible to demyelination and axonal degeneration. In this respect, it is intriguing that two proteins expressed by myelinating glia and clustered in the paranodes and juxtaparanodes, neurofascin and TAG-1, respectively, are targets of autoimmune responses in patients with multiple sclerosis (Mathey et al., 2007; Derfuss et al., 2009). This highlights the importance of deciphering the role of molecules underlying axoglial interactions. Overall, our results indicate for the first time a key role for TAG-1 expressed by glial cells in the organization of CNS myelinated fibers as well as in the axonal organization and myelination of the optic nerve. Glial TAG-1, in the absence of the axonal form, is able to completely reverse the molecular juxtaparanodal phenotype of Tag-1 ${ }^{-1-}$ mice. The full rescue of the behavioral deficits detected in homozygous mutants by the exclusive expression of glial TAG-1 further emphasizes the importance of this form. Our data point to the fact that TAG-1 expressed by oligodendrocytes is indispensible for the proper architecture of myelinated fibers.

\section{References}

Bongarzone ER, Campagnoni CW, Kampf K, Jacobs EC, Handley VW, Schonmann V, Campagnoni AT (1999) Identification of a new exon in the myelin proteolipid protein gene encoding novel protein isoforms that are restricted to the somata of oligodendrocytes and neurons. J Neurosci 19:8349-8357.

Bonnon C, Goutebroze L, Denisenko-Nehrbass N, Girault JA, Faivre-Sarrailh C (2003) The paranodal complex of F3/contactin and caspr/paranodin traffics to the cell surface via a non-conventional pathway. J Biol Chem 278:48339-48347.

Brinkmann BG, Agarwal A, Sereda MW, Garratt AN, Müller T, Wende H, Stassart RM, Nawaz S, Humml C, Velanac V, Radyushkin K, Goebbels S, 
Fischer TM, Franklin RJ, Lai C, Ehrenreich H, Birchmeier C, Schwab MH, Nave KA (2008) Neuregulin-1/ErbB signaling serves distinct functions in myelination of the peripheral and central nervous system. Neuron 59:581-595.

Carelli V, Ross-Cisneros FN, Sadun AA (2002) Optic nerve degeneration and mitochondrial dysfunction: genetic and acquired optic neuropathies. Neurochem Int 40:573-584.

Charles P, Tait S, Faivre-Sarrailh C, Barbin G, Gunn-Moore F, DenisenkoNehrbass N, Guennoc AM, Girault JA, Brophy PJ, Lubetzki C (2002) Neurofascin is a glial receptor for the paranodin/Caspr-contactin axonal complex at the axoglial junction. Curr Biol 12:217-220.

Chatzopoulou E, Miguez A, Savvaki M, Levasseur G, Muzerelle A, Muriel MP, Goureau O, Watanabe K, Goutebroze L, Gaspar P, Zalc B, Karagogeos D, Thomas JL (2008) Structural requirement of TAG-1 for retinal ganglion cell axons and myelin in the mouse optic nerve. J Neurosci 28:7624-7636.

Denaxa M, Chan CH, Schachner M, Parnavelas JG, Karagogeos D (2001) The adhesion molecule TAG-1 mediates the migration of cortical interneurons from the ganglionic eminence along the corticofugal fiber system. Development 128:4635-4644.

Dere E, Huston JP, De Souza Silva MA (2007) The pharmacology, neuroanatomy and neurogenetics of one-trial object recognition in rodents. Neurosci Biobehav Rev 31:673-704.

Derfuss T, Parikh K, Velhin S, Braun M, Mathey E, Krumbholz M, Kümpfel T, Moldenhauer A, Rader C, Sonderegger P, Pöllmann W, Tiefenthaller C, Bauer J, Lassmann H, Wekerle H, Karagogeos D, Hohlfeld R, Linington C, Meinl E (2009) Contactin-2/TAG-1-directed autoimmunity is identified in multiple sclerosis patients and mediates gray matter pathology in animals. Proc Natl Acad Sci U S A 106:8302-8307.

Faivre-Sarrailh C, Gauthier F, Denisenko-Nehrbass N, Le Bivic A, Rougon G, Girault JA (2000) The glycosylphosphatidyl inositol-anchored adhesion molecule F3/contactin is required for surface transport of paranodin/ contactin-associated protein (caspr). J Cell Biol 149:491-502.

Fitzli D, Stoeckli ET, Kunz S, Siribour K, Rader C, Kunz B, Kozlov SV, Buchstaller A, Lane RP, Suter DM, Dreyer WJ, Sonderegger P (2000) A direct interaction of axonin-1 with NgCAM-related cell adhesion molecule (NrCAM) results in guidance, but not growth of commissural axons. J Cell Biol 149:951-968.

Fruttiger M, Karlsson L, Hall AC, Abramsson A, Calver AR, Boström H, Willetts K, Bertold CH, Heath JK, Betsholtz C, Richardson WD (1999) Defective oligodendrocyte development and severe hypomyelination in PDGF-A knockout mice. Development 126:457-467.

Fukamauchi F, Aihara O, Wang YJ, Akasaka K, Takeda Y, Horie M, Kawano H, Sudo K, Asano M, Watanabe K, Iwakura Y (2001) TAG-1-deficient mice have marked elevation of adenosine A1 receptors in the hippocampus. Biochem Biophys Res Commun 281:220-226.

Furley AJ, Morton SB, Manalo D, Karagogeos D, Dodd J, Jessell TM (1990) The axonal glycoprotein TAG-1 is an immunoglobulin superfamily member with neurite outgrowth-promoting activity. Cell 61:157-170.

Fuss B, Mallon B, Phan T, Ohlemeyer C, Kirchhoff F, Nishiyama A, Macklin WB (2000) Purification and analysis of in vivo-differentiated oligodendrocytes expressing the green fluorescent protein. Dev Biol 218:259-274.

Garbern JY, Cambi F, Tang XM, Sima AA, Vallat JM, Bosch EP, Lewis R, Shy M, Sohi J, Kraft G, Chen KL, Joshi I, Leonard DG, Johnson W, Raskind W, Dlouhy SR, Pratt V, Hodes ME, Bird T, Kamholz J (1997) Proteolipid protein is necessary in peripheral as well as central myelin. Neuron 19:205-218.

Girault JA, Peles E (2002) Development of nodes of Ranvier. Curr Opin Neurobiol 12:476-485.

Gómez-Casati ME, Murtie J, Taylor B, Corfas G (2010) Cell-specific inducible gene recombination in postnatal inner ear supporting cells and glia. J Assoc Res Otolaryngol 11:19-26.

Griffiths IR, Dickinson P, Montague P (1995) Expression of the proteolipid protein gene in glial cells of the post-natal peripheral nervous system of rodents. Neuropathol Appl Neurobiol 21:97-110.

Griffiths I, Klugmann M, Anderson T, Yool D, Thomson C, Schwab MH, Schneider A, Zimmermann F, McCulloch M, Nadon N, Nave KA (1998) Axonal swellings and degeneration in mice lacking the major proteolipid of myelin. Science 280:1610-1613.

Karagogeos D, Morton SB, Casano F, Dodd J, Jessell TM (1991) Developmental expression of the axonal glycoprotein TAG-1: differential regulation by central and peripheral neurons in vitro. Development 112:51-67.

Kim HJ, DiBernardo AB, Sloane JA, Rasband MN, Solomon D, Kosaras B,
Kwak SP, Vartanian TK (2006) WAVE1 is required for oligodendrocyte morphogenesis and normal CNS myelination. J Neurosci 26:5849-5859.

Kunz S, Spirig M, Ginsburg C, Buchstaller A, Berger P, Lanz R, Rader C, Vogt L, Kunz B, Sonderegger P (1998) Neurite fasciculation mediated by complexes of axonin-1 and $\mathrm{Ng}$ cell adhesion molecule. J Cell Biol 143:1673-1690.

Kyriakopoulou K, de Diego I, Wassef M, Karagogeos D (2002) A combination of chain and neurophilic migration involving the adhesion molecule TAG-1 in the caudal medulla. Development 129:287-296.

Lieberoth A, Splittstoesser F, Katagihallimath N, Jakovcevski I, Loers G, Ranscht B, Karagogeos D, Schachner M, Kleene R (2009) Lewis(x) and alpha2,3-sialyl glycans and their receptors TAG-1, Contactin, and L1 mediate CD24-dependent neurite outgrowth. J Neurosci 29:6677-6690.

Liu Y, Halloran MC (2005) Central and peripheral axon branches from one neuron are guided differentially by Semaphorin3D and transient axonal glycoprotein-1. J Neurosci 25:10556-10563.

Ma QH, Futagawa T, Yang WL, Jiang XD, Zeng L, Takeda Y, Xu RX, Bagnard D, Schachner M, Furley AJ, Karagogeos D, Watanabe K, Dawe GS, Xiao ZC (2008) A TAG1-APP signalling pathway through Fe65 negatively modulates neurogenesis. Nat Cell Biol 10:283-294.

Mathey EK, Derfuss T, Storch MK, Williams KR, Hales K, Woolley DR, Al-Hayani A, Davies SN, Rasband MN, Olsson T, Moldenhauer A, Velhin S, Hohlfeld R, Meinl E, Linington C (2007) Neurofascin as a novel target for autoantibody-mediated axonal injury. J Exp Med 204:2363-2372.

Mattson MP, van Praag H (2008) TAGing APP constrains neurogenesis. Nat Cell Biol 10:249-250.

Meiri N, Ghelardini C, Tesco G, Galeotti N, Dahl D, Tomsic D, Cavallaro S, Quattrone A, Capaccioli S, Bartolini A, Alkon DL (1997) Reversible antisense inhibition of Shaker-like Kv1.1 potassium channel expression impairs associative memory in mouse and rat. Proc Natl Acad Sci U S A 94:4430-4434.

Miller MJ, Kangas CD, Macklin WB (2009) Neuronal expression of the proteolipid protein gene in the medulla of the mouse. J Neurosci Res 87:2842-2853.

Oliver PL, Keays DA, Davies KE (2007) Behavioural characterisation of the robotic mouse mutant. Behav Brain Res 181:239-247.

Park J, Liu B, Chen T, Li H, Hu X, Gao J, Zhu Y, Zhu Q, Qiang B, Yuan J, Peng X, Qiu M (2008) Disruption of Nectin-like 1 cell adhesion molecule leads to delayed axonal myelination in the CNS. J Neurosci 28:12815-12819.

Parron C, Save E (2004) Comparison of the effects of entorhinal and retrosplenial cortical lesions on habituation, reaction to spatial and non-spatial changes during object exploration in the rat. Neurobiol Learn Mem 82:1-11.

Peles E, Nativ M, Lustig M, Grumet M, Schilling J, Martinez R, Plowman GD, Schlessinger J (1997) Identification of a novel contactin-associated transmembrane receptor with multiple domains implicated in proteinprotein interactions. EMBO J 16:978-988.

Pernet V, Joly S, Christ F, Dimou L, Schwab ME (2008) Nogo-A and myelinassociated glycoprotein differently regulate oligodendrocyte maturation and myelin formation. J Neurosci 28:7435-7444.

Poliak S, Peles E (2003) The local differentiation of myelinated axons at nodes of Ranvier. Nat Rev Neurosci 4:968-980.

Poliak S, Salomon D, Elhanany H, Sabanay H, Kiernan B, Pevny L, Stewart CL, Xu X, Chiu SY, Shrager P, Furley AJ, Peles E (2003) Juxtaparanodal clustering of Shaker-like $\mathrm{K}+$ channels in myelinated axons depends on Caspr2 and TAG-1. J Cell Biol 162:1149-1160.

Popko B, Puckett C, Lai E, Shine HD, Readhead C, Takahashi N, Hunt SW 3rd, Sidman RL, Hood L (1987) Myelin deficient mice: expression of myelin basic protein and generation of mice with varying levels of myelin. Cell 48:713-721.

Puckett C, Hudson L, Ono K, Friedrich V, Benecke J, Dubois-Dalcq M, Lazzarini RA (1987) Myelin-specific proteolipid protein is expressed in myelinating Schwann cells but is not incorporated into myelin sheaths. J Neurosci Res 18:511-518.

Saadati HG, Hsu HY, Heller KB, Sadun AA (1998) A histopathologic and morphometric differentiation of nerves in optic nerve hypoplasia and Leber hereditary optic neuropathy. Arch Ophthalmol 116:911-916.

Sadun AA (2002) Mitochondrial optic neuropathies. J Neurol Neurosurg Psychiatry 72:423-425.

Salzer JL (2003) Polarized domains of myelinated axons. Neuron 40:297-318. 
Salzer JL, Brophy PJ, Peles E (2008) Molecular domains of myelinated axons in the peripheral nervous system. Glia 56:1532-1540.

Savvaki M, Panagiotaropoulos T, Stamatakis A, Sargiannidou I, Karatzioula P, Watanabe K, Stylianopoulou F, Karagogeos D, Kleopa KA (2008) Impairment of learning and memory in TAG-1 deficient mice associated with shorter CNS internodes and disrupted juxtaparanodes. Mol Cell Neurosci 39:478-490.

Stoeckli ET, Kuhn TB, Duc CO, Ruegg MA, Sonderegger P (1991) The axonally secreted protein axonin-1 is a potent substratum for neurite growth. J Cell Biol 112:449-455.

Traka M, Dupree JL, Popko B, Karagogeos D (2002) The neuronal adhesion protein TAG-1 is expressed by Schwann cells and oligodendrocytes and is localized to the juxtaparanodal region of myelinated fibers. J Neurosci 22:3016-3024.

Traka M, Goutebroze L, Denisenko N, Bessa M, Nifli A, Havaki S, Iwakura Y, Fukamauchi F, Watanabe K, Soliven B, Girault JA, Karagogeos D (2003) Association of TAG-1 with Caspr2 is essential for the molecular organization of juxtaparanodal regions of myelinated fibers. J Cell Biol 162:1161-1172.

Tzimourakas A, Giasemi S, Mouratidou M, Karagogeos D (2007) Structurefunction analysis of protein complexes involved in the molecular archi- tecture of juxtaparanodal regions of myelinated fibers. Biotechnol J 2:577-583.

Volkmer H, Zacharias U, Nörenberg U, Rathjen FG (1998) Dissection of complex molecular interactions of neurofascin with axonin-1, F11, and tenascin-R, which promote attachment and neurite formation of tectal cells. J Cell Biol 142:1083-1093.

Wight PA, Duchala CS, Readhead C, Macklin WB (1993) A myelin proteolipid protein-LacZ fusion protein is developmentally regulated and targeted to the myelin membrane in transgenic mice. J Cell Biol 123:443-454

Wight PA, Duchala CS, Shick HE, Gudz TI, Macklin WB (2007) Expression of a myelin proteolipid protein (Plp)-lacZ transgene is reduced in both the CNS and PNS of Plp(jp) mice. Neurochem Res 32:343-351.

Wolman MA, Sittaramane VK, Essner JJ, Yost HJ, Chandrasekhar A, Halloran MC (2008) Transient axonal glycoprotein-1 (TAG-1) and lamininalpha1 regulate dynamic growth cone behaviors and initial axon direction in vivo. Neural Dev 3:6.

Zoumalan CI, Agarwal M, Sadun AA (2005) Optical coherence tomography can measure axonal loss in patients with ethambutol-induced optic neuropathy. Graefes Arch Clin Exp Ophthalmol 243:410-416. 